\title{
Service quality assessment in the academic library: Use of hybrid fuzzy expert system
}

\author{
${ }^{1}$ Ali Akbar Pourahmad, ${ }^{2}$ Mehdi Neshat, and ${ }^{3}$ Ahmad Baghi \\ ${ }^{1}$ Department of Information Science and Library, Shirvan Branch, Islamic Azad University, Shirvan, Iran. \\ ${ }^{2}$ Department of Computer Engineering, Shirvan Branch, Islamic Azad University, Shirvan, Iran. \\ ${ }^{3}$ Department of management science, Shirvan Branch, Islamic Azad University, Shirvan, Iran.
}

Accepted 21 March, 2012

\begin{abstract}
Library is one of the most important elements in the scientific development of every country, especially academic libraries which are the centers of research and study for scholars. The assessment of service quality of these libraries can promote their performance and increase users' satisfaction. In this paper, a hybrid fuzzy expert system is applied to investigate service quality assessment in the academic library. In order to design this system, the opinions of experts in the field of librarianship science are used. In addition, a general survey is carried out to obtain the opinions of students. This system is a combination of four fuzzy expert systems. After system design, it was tested and evaluated. The results indicated that the system with $\mathbf{9 8 . 0 0 2} \%$ accuracy can predict the quality of services provided by libraries and can determine the level of users' satisfaction. By making use of this system, we can evaluate the performance of academic libraries and identify their weakness and strength points. Moreover, it can improve the efficiency and increase the level of users' satisfaction.
\end{abstract}

Key words: Academic library, expert system, fuzzy logic, Library service assessment.

\section{INTRODUCTION}

Academic libraries are one the main components of an education and research system of every country. Their optimal and good performance attracts further students, professors as well as researchers. To achieve such an objective, libraries should provide specific conditions in which the researchers' knowledge is improved both qualitatively and quantitatively. The purpose of every library or information center is to improve the information requirements of people. In order to probe the quality of library services, assessment can be an effective instrument. Assessment in different organizations and institutions is carried out. Such an act is a matter of importance both for managers of organizations as well as users. The main objective of a library performance assessment is to achieve higher goals, such as increasing the level of users' satisfaction, and improving the level of efficiency and effectiveness for the sake of scientific advancement of the users. Plenty of studies,

\footnotetext{
*Corresponding author. E-mail: neshat_mehdi@yahoo.com
}

presented in Table 1, have done a lot in improving library services (Bertot, 2004). Various methods including SERVQUAL (Parasuraman et al., 1985, 1988; Hernon and Altman, 1996; Hernon et al., 1999), balanced scorecard (Kaplan and Norton, 1996; Self, 2003), ClimateQUAL ${ }^{\mathrm{TM}}$ (Kyrillidou et al., 2009), DigiQUAL (Kyrillidou and Giersch, 2005), LibQUAL ${ }^{+T M}$ (Waller et al., 2003; Cook and Heath, 2001b; Cook, 2002) etc., are used for assessment. A review, using LibQUAL ${ }^{+T M}$ model, of previous researches on the assessment of library services is presented in Table 2. In this study, a LibQUAL $^{+T M}$ model and a fuzzy expert system are utilized. Through identifying the most important parameters in quality of services, the model attempts to analyze the clients' attitudes. According to previously conducted studies, this model is one of the good ones designed to evaluate the quality of services provided by libraries (Cook et al., 2001a, 2003a; Shi and Levy, 2005; Calvert, 2008).

The application of LibQUAL+TM model assessment process has its own problems. The first problem is dealing with subjectivity and ambiguous judgments 
Table 1. Overview of selected evaluative approach.

\begin{tabular}{|c|c|c|c|}
\hline Evaluation approach & Description & Examples of Evaluative practices & Applications \\
\hline Outputs assessment & $\begin{array}{l}\text { Collection of counts from use of resources, } \\
\text { services, or programming }\end{array}$ & $\begin{array}{l}\text { 1. Collection of traditional counts, for example, } \\
\text { reference, circulation, etc. } \\
\text { 2. Focus groups } \\
\text { 3. Interviews }\end{array}$ & $\begin{array}{l}\text { 1. Evaluation of resources, services, an } \\
\text { programs } \\
\text { 2. Planning }\end{array}$ \\
\hline $\begin{array}{l}\text { Performance } \\
\text { measures }\end{array}$ & $\begin{array}{l}\text { Developed for evaluating the presentation } \\
\text { and/ or delivery of specific library resources, } \\
\text { services, or programs }\end{array}$ & $\begin{array}{l}\text { 1. Availability studies } \\
\text { 2. Usability studies. } \\
\text { 3. Web-page analysis } \\
\text { 4. Content analysis } \\
\text { 5. Functionality analysis }\end{array}$ & $\begin{array}{l}\text { 1. Usability of resources, services, or programs } \\
\text { 2. Availability of resources } \\
\text { 3. Determine efficiency or effectiveness } \\
\text { of presentation of resources, services, } \\
\text { or programs, etc. }\end{array}$ \\
\hline $\begin{array}{l}\text { Service } \\
\text { quality }\end{array}$ & $\begin{array}{l}\text { Developed to determine the overall quality of } \\
\text { both traditional and network-based resources } \\
\text { and services }\end{array}$ & $\begin{array}{l}\text { 1. SERVQUAL } \\
\text { 2. LibQUAL+ } \\
\text { 3. Balanced Scorecard } \\
\text { 4. Best Practices } \\
\text { 5. Benchmarking }\end{array}$ & $\begin{array}{l}\text { 1.User satisfaction with library services } \\
\text { 2. Library staff/management appraisal } \\
\text { and/or desired level of service provision }\end{array}$ \\
\hline $\begin{array}{l}\text { Outcomes } \\
\text { assessment }\end{array}$ & $\begin{array}{l}\text { Developed to assess the effects of } \\
\text { programming on patrons in terms of benefits } \\
\text { to patrons }\end{array}$ & $\begin{array}{l}\text { 1. Outcomes as a product of programming } \\
\text { 2. Outcomes as the effect of programming }\end{array}$ & $\begin{array}{l}\text { 1. As a product, initial measurable effect of } \\
\text { programs on patrons } \\
2 \text {. As an effect, initial to long-term evaluation of } \\
\text { measurable benefits for patrons based on } \\
\text { specific programming }\end{array}$ \\
\hline
\end{tabular}

Table 2. A Review of studies Conducted on LibQUAL ${ }^{+T M}$.

\begin{tabular}{|c|c|}
\hline Author & Paper \\
\hline Nimsomboon and Nagata (2003) & Assessment of Library Service Quality as Thammasat library system \\
\hline Kyrillidou et al. (2003) & Cross-cultural implementation of LibQUAL+ ${ }^{\mathrm{TM}}$ : the French Language experience \\
\hline Thompson et al. (2006) & How you can evaluate the integrity of your library service quality assessment data intercontinental libqualanalyses used as concrete \\
\hline Sahu (2007) & Measuring service quality in an academic library: an Indian case study \\
\hline Kiran (2010) & Service quality and customer satisfaction in academic libraries: Perspectives from a Malaysian university \\
\hline Thompson et al. (2009) & $\begin{array}{l}\text { Item sampling in service quality assessment surveys to improve response rates and reduce respondent burden. The"LibQUAL }{ }^{+} \text {Lite" } \\
\text { example }\end{array}$ \\
\hline
\end{tabular}


Table 3. Dimensions of library service quality in LibQUAL+TM .

\begin{tabular}{|c|c|c|c|}
\hline 2000 & 2001 & 2002 & 2003 \\
\hline 41-items & 56-items & 25-items & 22-items \\
\hline Affect of service & Affect of service & Service affect & Service affect \\
\hline Library as place & Library as place & Library as place & Library as place \\
\hline Reliability & Reliability & Personal control & Information control \\
\hline Provision of physical collection & Self - reliance & Information access & ----------------------- \\
\hline Access to information & Access to information & ---------------------- & ----------------------- \\
\hline
\end{tabular}

people make when they convert their opinions into numbers. The second problem is that subjective judgment and preferences of assessors have significant implications on the results (Lin et al., 2006). To solve this problem, fuzzy logic toolkit and expert systems can be utilized. For modeling and dealing with uncertainty as well as ambiguity the evaluators may have, the fuzzy logic applies oral terms and corresponds them to appropriate membership functions in order to provide more accurate and optimal analysis about the indexes (Shahraki et al., 2011; Gopalakrishnan and Raghavan, 2003; Perez et al., 2010). The combination of experts and fuzzy logic yields a highly accurate system.

In the majority of management fields, service assessment and acquisition of customer satisfaction are the most important reasons leading to success of company. Different terms such as "excellent" and/or "average" are used to refer to service quality. These terms are replaced with numbers in system modeling. However, those numbers are chosen subjectively; whereby, the next assessment process would be more difficult. Fuzzy logic can be a good tool for modeling these management systems (Dodangeh et al., 2011; Jiang, 2009; Jamali and Tooranloo, 2009). Fuzzy expert systems have great flexibility and when the input data have a lot of noise, those have good performance.

Following on, various methods of library service quality assessment are discussed, reviewed of experimental results and finally conclusion.

\section{METHODS}

\section{Library service quality}

The NSF/NSDL-funded part of the project has the overarching goal of developing a digital library service quality assessment process that enhances student learning by permitting the allocation of resources to areas of user-identified need. The goal is to develop a total market survey appropriate for the digital library environment. To fulfill that goal, our project seeks to achieve the following objectives and outcomes within the NSF/NSDL community: (a) define the dimensions of digital library service quality from the perspective of the users; (b) develop a tool for measuring user perceptions and expectations of digital library service quality across NSDL digital library contexts; (c) identify digital library "best practices" that permit generalizations across operations and development platforms; (d) enhance student learning by effectively managing user perceptions and expectations of digital library services; (e) establish a digital library service quality assessment program as an integral part of the library service quality assessment program at ARL (Heath et al., 2002); and (f) institutionalize continuous product and process evaluation efforts directed toward positive and timely management of outcomes.

Based on the afore-mentioned reasons, the need for library service quality assessment is absolutely evident. However, the applied model may not cover all aspects of library services, but the way this work is important. In this research, LibQUAL ${ }^{+T M}$ model is used in form of a combination. The specifications of assessment and the development process are presented in Table 3.

In this study, the developed parameters of year 2003 are applied. These parameters are categorized into three general groups presented in Table 4. These parameters are the inputs of fuzzy expert systems.

\section{What is LibQUAL+ ${ }^{\mathrm{TM}}$ ?}

LibQUAL+ ${ }^{T M}$ is an innovative, technology-based suite of services aimed at measuring library service quality. LibQUAL+ ${ }^{\mathrm{TM}}$ is the result of extensive research and development undertaken by $A R L$ and Texas $A$ and $M$ University, supported in part by the U.S. Department of Education's Fund for the Improvement of Postsecondary Education (FIPSE) and the National Science Foundation (NSF). It is one of the ARL new measures initiative projects aimed at developing assessment tools and e-services for evaluating the library of the 21 st century. The LibQUAL+TM eservice component is emerging as a robust service operation, enabling libraries to engage in user-based assessment not only across institutions but across borders and language barriers for a modest participation fee. Whether a similar service can be developed for digital library operations, tentatively called e-QUAL (for "electronic quality"), is an open challenge that is currently being explored with the funding available to this project from NSF/NSDL (National Science Digital Library).

The project builds on the theoretical foundations of the gap theory of service quality, and in particular on the SERVQUAL measurement of the gap between customers' expectations and perceptions of service quality. After extensive iterative and continuous qualitative and quantitative re-grounding and four years of implementations, the re-grounded instrument known as LibQUAL+TM has evolved into a total market survey. Following the spring 2003 survey identified three dimensions of library service quality: library as place (LP), information control (IC), and affect of service (AS). Table 3 outlines the evolution of the dimensions in the LibQUAL+ ${ }^{\mathrm{TM}}$ protocol. The LibQUAL+ ${ }^{\mathrm{TM}}$ protocol has successfully measured perceptions of library service quality across more than 400 institutions since 2000. It has grown from 12 participating institutions in 2000 to 43 institutions in 2001, 164 institutions in 2002, and 308 institutions in 2003. The LibQUAL+ ${ }^{\mathrm{TM}}$ survey instrument has successfully collected data from more than 5,000 users in 2000; 20,000+ users in 2001,70,000+ users in 2002, and 120,000 + users in 2003 (Cook et al., 2003a). 
Table 4. List of assessment parameters in LibQUAL ${ }^{+T M}$ (2003) Model.

\begin{tabular}{|c|c|c|}
\hline $\mathbf{S} / \mathbf{N}$ & Main Item & Subdivision Item \\
\hline 1 & Affect of service (AS) & $\begin{array}{l}\text { 1.1. (AS1) Employees who instill confidence in users } \\
\text { 1.2. (AS2) Readiness to respond to users' questions } \\
\text { 1.3. (AS3) Willingness to help users } \\
\text { 1.4. (AS4) Dependability in handling users' problems } \\
\text { 1.5. (AS5) Giving users individual attention } \\
\text { 1.6. (AS6) Employees who have the knowledge } \\
\text { 1.7. (AS7) Employees who are consistently courteous } \\
\text { 1.8. (AS8) Employees who deal with users in a caring fashion } \\
\text { 1.9. (AS9) Employees who understand the needs of their users }\end{array}$ \\
\hline 2 & Library as place & $\begin{array}{l}\text { 2.1. (LP1) Quiet space for individual activities } \\
\text { 2.2. (LP2) A comfortable and inviting location } \\
\text { 2.3. (LP3) Library space that inspires study and learning } \\
\text { 2.4. (LP4) Community space for group learning and group study } \\
\text { 2.5. (LP5) A getaway for study, learning or research }\end{array}$ \\
\hline 3 & Information control & $\begin{array}{l}\text { 3.1. (IC1) Print and/or electronic journal collections } \\
\text { 3.2. (IC2) The printed library materials I need for my work } \\
\text { 3.3. (IC3) The electronic information resources I need } \\
\text { 3.4. (IC4) Easy-to-use access tools } \\
\text { 3.5. (IC5) A library Web site enabling me } \\
\text { 3.6. (IC6) Modern equipment to access information } \\
\text { 3.7. (IC7) Making information easily accessible for independent use } \\
\text { 3.8. (IC8) Electronic resources accessible from home or office }\end{array}$ \\
\hline
\end{tabular}

In the ten years since its inception in 2000 (Thompson, 2007), $\mathrm{LibQUAL}^{+}$has been used to collect data from more than 1.25 million library users from more than 1,000 institutions! LibQUAL ${ }^{+}$ has now been used in 22 different countries: the USA ,Canada , Mexico, Bahamas, Australia, New Zealand, the UK (England, Scotland, Wales), France, Ireland, Belgium, The Netherlands, Switzerland, Denmark, Finland, Norway, Sweden, Egypt, United Arab Emirates, South Africa, Hong Kong, Singapore, and Japan. Currently, the system supports 15 languages: Afrikaans, American English, British English, and Chinese (Traditional), Danish, Dutch, Finnish, and French (Canadian), French (European), German, Norwegian, Spanish, Swedish, Welsh and Japanese. The development and use of $\mathrm{LibQUAL}^{+}$has been documented in a host of academic outlets (Cook et al., 2001c; Thompson et al., 2008).

\section{Hybrid fuzzy expert system}

A fuzzy expert system includes: fuzzification, inference engine, database, and defuzzification .This hybrid system combined of four fuzzy inference systems (FIS). Three systems - Affect of services
(AS), library as place (LP), and information control (IC) -work in parallel with each other and send their outputs to the fourth system which is library service quality (LSQ). The latter yields the final product. An overall view of the hybrid fuzzy expert system is presented in Figure 1.

\section{Service effect fuzzy system}

This system includes 9 inputs each of which are implemented through applying different membership functions. The output of system is the degree of effectiveness of services. Figure 2 illustrates the input and output membership functions of this system. Following on, fuzzification equations will be discussed. All inputs and outputs range from 0 to 100 in order to make the system testing more meaningful. Figure 2 shows the membership functions and their range by considering the opinions of library experts and university students. To develop this hybrid system, MATLAB is used.

In order to determine the membership functions in fuzzy logic, specific fuzzy Equations 1 are used. The fuzzification equations related to service effect system is explained in the following.

$$
\mu_{\text {few }}(A S 1)=\left\{\begin{array}{cc}
0 & x<0 \\
\frac{40-x}{40} & 0 \leq x<40
\end{array} \quad \mu_{\text {normal }}(A S 1)=\left\{\begin{array}{cc}
\frac{x-20}{30} & 20 \leq x<50 \\
\frac{80-x}{30} & 50 \leq x<80
\end{array} \mu_{\text {many }}(A S 1)=\left\{\begin{array}{cc}
0 & x>100 \\
\frac{x-60}{40} & 80 \leq x \leq 100
\end{array}\right.\right.\right.
$$


(AS2) Readiness to respond to users' questions

$$
\begin{aligned}
& \mu_{V L}(A S 2)=\left\{\begin{array}{cc}
0 & x<0 \\
1 & 0 \leq x \leq 4 \\
\frac{36-x}{32} & 4<x \leq 36
\end{array} \quad \mu_{L}(A S 2)=\left\{\begin{array}{cc}
\frac{x-20}{20} & 20 \leq x<40 \\
\frac{60-x}{20} & 40 \leq x<60
\end{array} \quad \mu_{N}(A S 2)=\left\{\begin{array}{cc}
\frac{x-40}{20} & 40 \leq x<60 \\
\frac{80-x}{20} & 60 \leq x \leq 80
\end{array}\right.\right.\right. \\
& \mu_{H}(A S 2)=\left\{\begin{array}{ll}
\frac{x-65}{15} & 65 \leq x<80 \\
\frac{90-x}{10} & 80 \leq x \leq 90
\end{array} \quad \mu_{V H}(A S 2)=\left\{\begin{array}{cc}
0 & x>100 \\
1 & 90 \leq x \leq 100 \\
\frac{x-75}{25} & 75 \leq x<90
\end{array}\right.\right. \\
& \text { (AS3) Willingness to help users } \\
& \mu_{L}(A S 3)=\left\{\begin{array}{cc}
0 & x<0 \\
1 & 0 \leq x \leq 10 \\
\frac{40-x}{30} & 10<x \leq 40
\end{array}\right. \\
& \mu_{N}(A S 3)=\left\{\begin{array}{ll}
\frac{x-25}{25} & 25 \leq x<50 \\
\frac{75-x}{25} & 50 \leq x<75
\end{array} \quad \mu_{H}(A S 3)=\left\{\begin{array}{cc}
0 & x>100 \\
1 & 90 \leq x \leq 100 \\
\frac{x-60}{30} & 60 \leq x<90
\end{array}\right.\right. \\
& \mu_{V L}(A S 5)=e^{\frac{-(x-0)^{2}}{2 * 12^{2}}} \quad \mu_{L}(A S 5)=e^{\frac{-(x-30)^{2}}{2 * 9^{2}}} \quad \mu_{M}(A S 5)=e^{\frac{-(x-60)^{2}}{2 * 9^{2}}} \quad \mu_{H}(A S 5)=e^{\frac{-(x-100)^{2}}{2^{*} 15^{2}}} \\
& \mu_{V L}(O A S)=\left\{\begin{array}{cc}
0 & x<0 \\
1 & 0 \leq x \leq 10 \\
\frac{30-x}{20} & 10<x \leq 30
\end{array} \quad \mu_{L}(O A S)=\left\{\begin{array}{cc}
\frac{x-40}{25} & 15 \leq x<40 \\
\frac{60-x}{20} & 40 \leq x<60
\end{array} \quad \mu_{N}(O A S)=\left\{\begin{array}{cc}
\frac{x-40}{15} & 40 \leq x<55 \\
\frac{70-x}{15} & 55 \leq x \leq 70
\end{array}\right.\right.\right. \\
& \mu_{H}(O A S)=\left\{\begin{array}{ll}
\frac{x-60}{20} & 60 \leq x<80 \\
\frac{95-x}{15} & 80 \leq x \leq 95
\end{array} \quad \mu_{V H}(O A S)=\left\{\begin{array}{cc}
0 & x>100 \\
1 & 95 \leq x \leq 100 \\
\frac{x-82}{13} & 82 \leq x<95
\end{array}\right.\right.
\end{aligned}
$$

After fuzzification of the inputs, system's fuzzy rules should be set. In every fuzzy expert system, the fuzzy rules are the most important part. These rules are of a form similar to if <conditions $>$ then $<$ statement>. To set the rules, the opinions of library experts and students can be used. These rules examine the relationship between system's inputs in different situation and will yield an appropriate output in every status. The service effect fuzzy system has 22 independent rules. Figure 3 presents the rules of service effect fuzzy system considering each specific input. The final step in designing a fuzzy expert system is defuzzification.

The input for the defuzzification process is a fuzzy set (the aggregate output fuzzy set) and the output is a single number. As much as fuzziness helps the rule evaluation during the intermediate steps, the final desired output for each variable is generally a single number. However, the aggregate of a fuzzy set encompasses a range of output values, and so must be defuzzified in order to resolve a single output value from the set .

Perhaps the most popular defuzzification method is the centroid calculation, which returns the center of area under the curve. There are five built-in methods supported: centroid, bisector, middle of maximum (the average of the maximum value of the output set), largest of maximum, and smallest of maximum.

In this fuzzy system, centroid defuzzification technique is utilized. This method is also known as center of gravity or center of area defuzzification. This technique was developed by Sugeno in 1985. This is the most commonly used technique and is very accurate. The centroid defuzzification technique can be expressed as:

$$
X^{*}=\frac{\int \mu_{i}(x) x d x}{\int \mu_{i}(x) d x}
$$



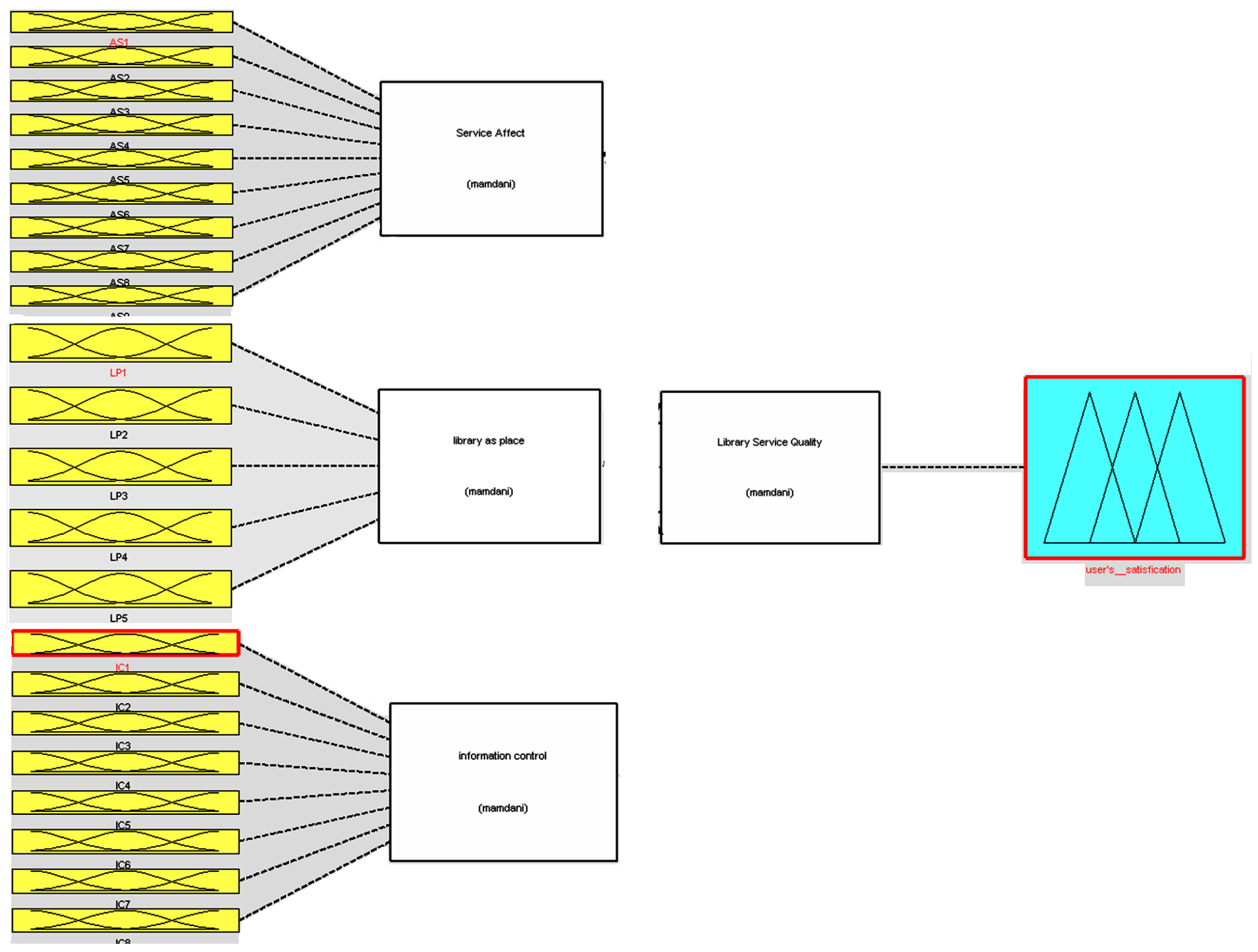

Figure 1. Hybrid fuzzy expert system for library services quality assessment. 


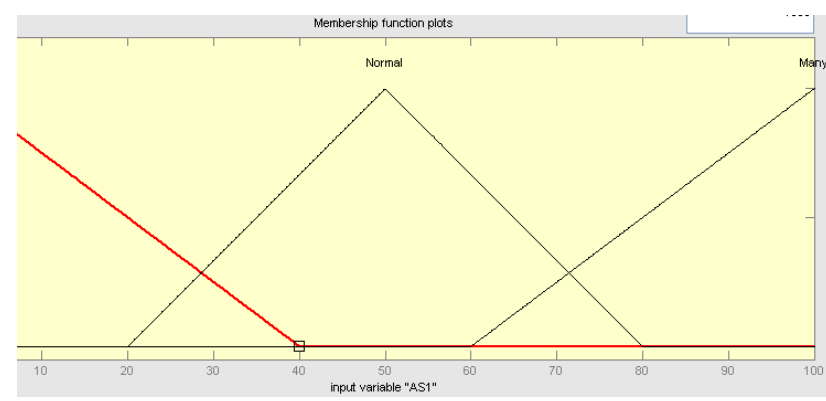

(AS1)

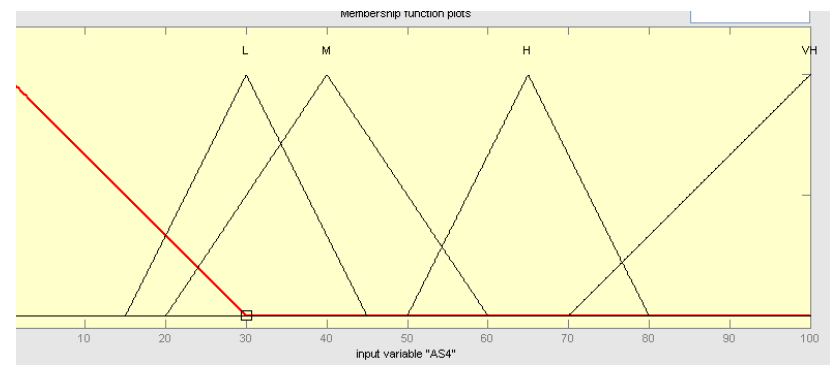

(AS4)

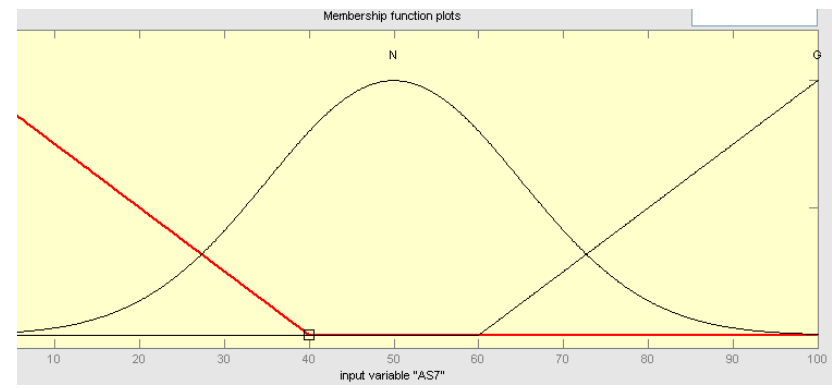

(AS7)

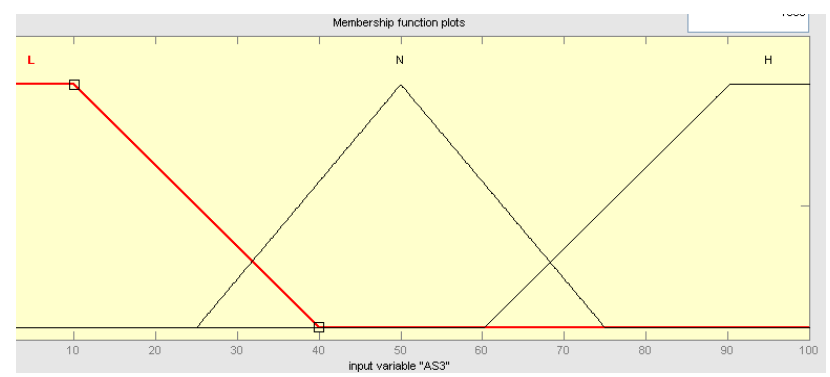

(AS3)

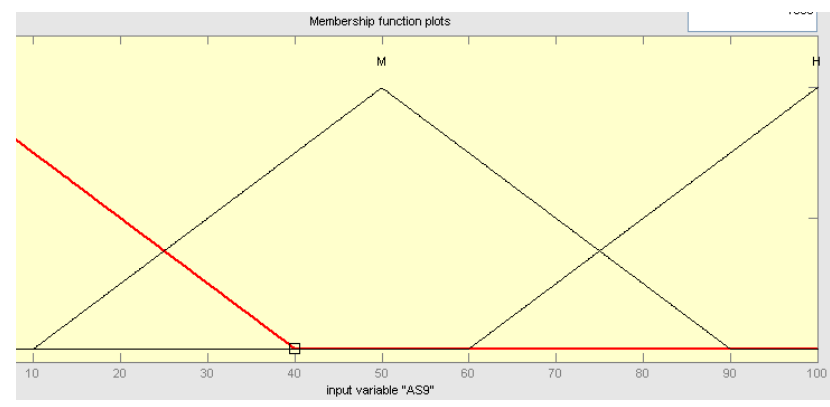

(AS9)

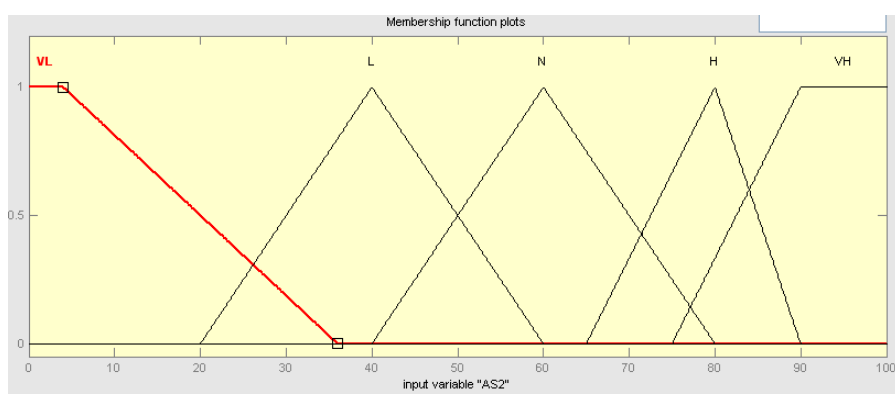

(AS2)

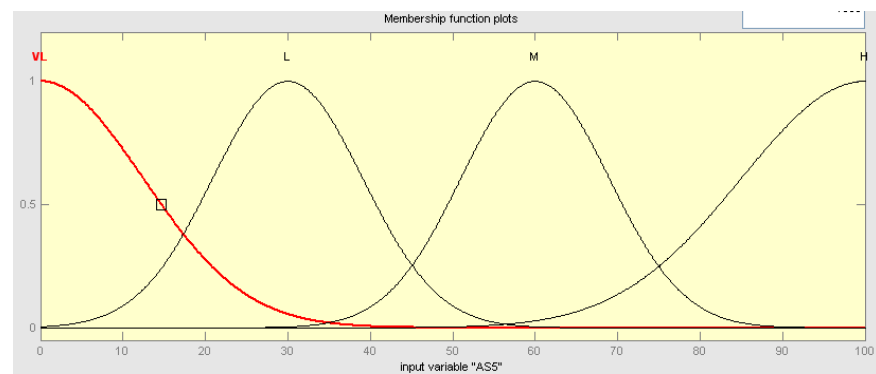

(AS5)

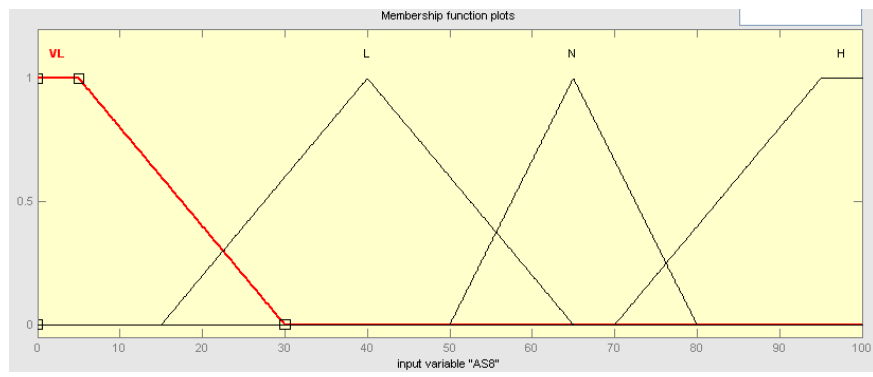

(AS8)

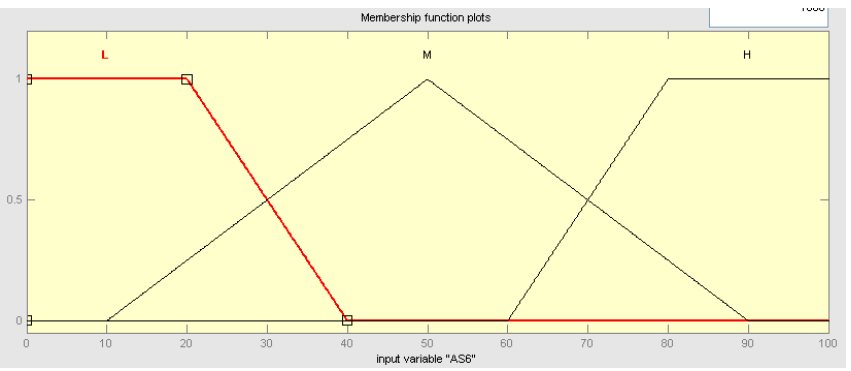

(AS6)

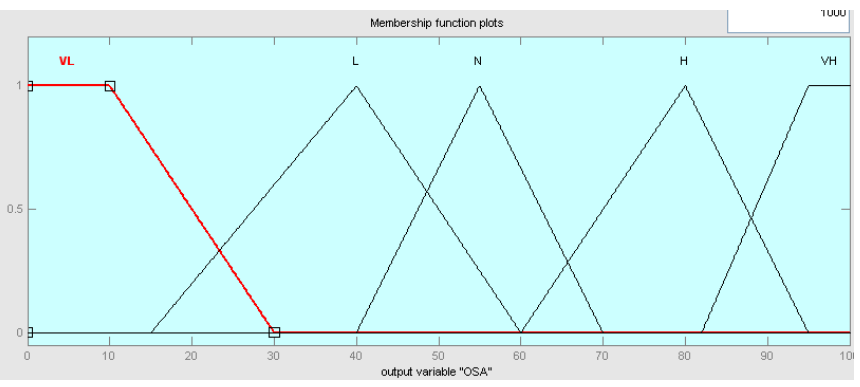

(Out put AS)

Figure 2. Fuzzy membership functions in service effectiveness system. 
Where $x^{*}$ is the defuzzified output, $\mu_{i}(x)$ is the aggregated membership function and $x$ is the output variable. The only disadvantage of this method is that it is computationally difficult for complex membership functions.

\section{Library place fuzzy system}

The place of library has significant influence on users. The usefulness of library environment as a place for study, participation in scientific projects, as well as thinking and conducting research can play a great part in enhancement of users' satisfaction.

This fuzzy expert system has 5 inputs and 1 output. The inputs are presented in Table 4. Figure 4 shows fuzzy inputs of library place system.

The LP1 input has 5 fuzzy membership functions including (very small (VS), small(S), normal (N), big (B), very big (VB)). The VB and VS are trapezoidal membership functions, while the others are triangular membership functions. To fuzzification the LP1 input membership functions; following Equation 3 is used.

(LP1) Quiet space for individual activities (3)

$$
\begin{aligned}
& \mu_{V S}(L P 1)=\left\{\begin{array}{cc}
0 & x<0 \\
1 & 0 \leq x \leq 10 \\
\frac{20-x}{10} & 10<x \leq 20
\end{array} \quad \mu_{S}(L P 1)=\left\{\begin{array}{cc}
\frac{x-10}{20} & 10 \leq x<30 \\
\frac{50-x}{20} & 30 \leq x<50
\end{array} \quad \mu_{N}(L P 1)=\left\{\begin{array}{cc}
\frac{x-40}{15} & 40 \leq x<55 \\
\frac{70-x}{15} & 55 \leq x \leq 70
\end{array}\right.\right.\right. \\
& \mu_{B}(L P 1)=\left\{\begin{array}{ll}
\frac{x-60}{15} & 60 \leq x<75 \\
\frac{90-x}{15} & 75 \leq x \leq 90
\end{array} \quad \mu_{V B}(L P 1)=\left\{\begin{array}{cc}
0 & x>100 \\
1 & 95 \leq x \leq 100 \\
\frac{x-75}{20} & 75 \leq x<95
\end{array}\right.\right.
\end{aligned}
$$

The LP2 input (a comfortable and inviting location) has 4 Gaussian fuzzy membership functions which are (VIC (very inconvenient), IC (inconvenient), C (convenient), VC (very convenient)). To fuzzification these functions, following Equation 4 is used.

$$
\mu_{V I C}(L P 2)=e^{\frac{-(x-0)^{2}}{2 * 12^{2}}} \quad \mu_{I C}(L P 2)=e^{\frac{-(x-30)^{2}}{2 * 12^{2}}} \quad \mu_{C}(L P 2)=e^{\frac{-(x-60)^{2}}{2 * 15^{2}}} \quad \mu_{V C}(L P 2)=e^{\frac{-(x-100)^{2}}{2 * 12^{2}}}
$$

The LP3 (Library space that inspires study and learning) input has 3 fuzzy membership functions including ((B (bad), N (normal), G (good)). The $G$ and $B$ are trapezoidal membership functions, while the others are triangular membership functions. To fuzzification the LP3 input membership functions; following Equation 5 is used.

(LP3) Library space that inspires study and learning (5)

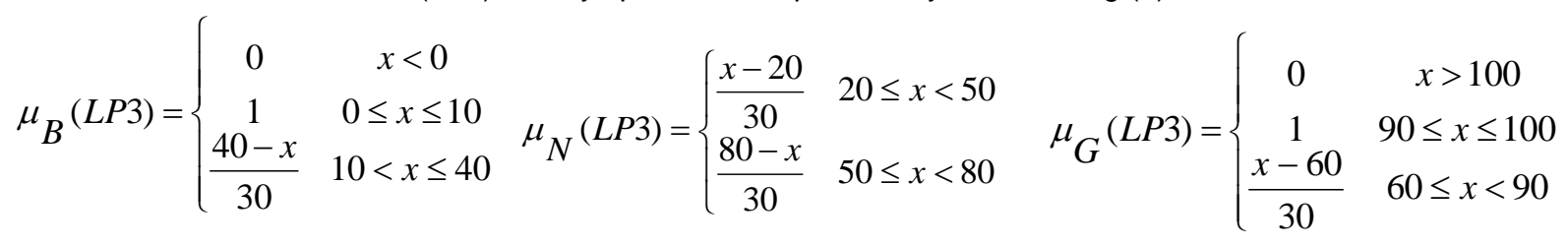

The LP4 (community space for group learning and group study) input has 5 fuzzy membership functions including (VB, B, N, G,
VG). All input membership functions are triangular. To fuzzification the LP4 input membership functions; following Equation 6 is used.

(LP4) Community space for group learning and group study (6)

$$
\begin{gathered}
\mu_{V B}(L P 4)=\left\{\begin{array}{cc}
0 & x<0 \\
1 & x=0 \\
\frac{20-x}{20} & 0<x \leq 20
\end{array} \quad \mu_{B}(L P 4)=\left\{\begin{array}{cc}
\frac{x-10}{20} & 10 \leq x<30 \\
\frac{50-x}{20} & 30 \leq x<50
\end{array} \quad \mu_{N}(L P 4)=\left\{\begin{array}{cc}
\frac{x-35}{15} & 35 \leq x<50 \\
\frac{65-x}{15} & 50 \leq x \leq 65
\end{array}\right.\right.\right. \\
\mu_{G}(L P 4)=\left\{\begin{array}{ccc}
\frac{x-55}{15} & 55 \leq x<70 \\
\frac{85-x}{15} & 70 \leq x \leq 85 & x>100
\end{array}\right.
\end{gathered}
$$




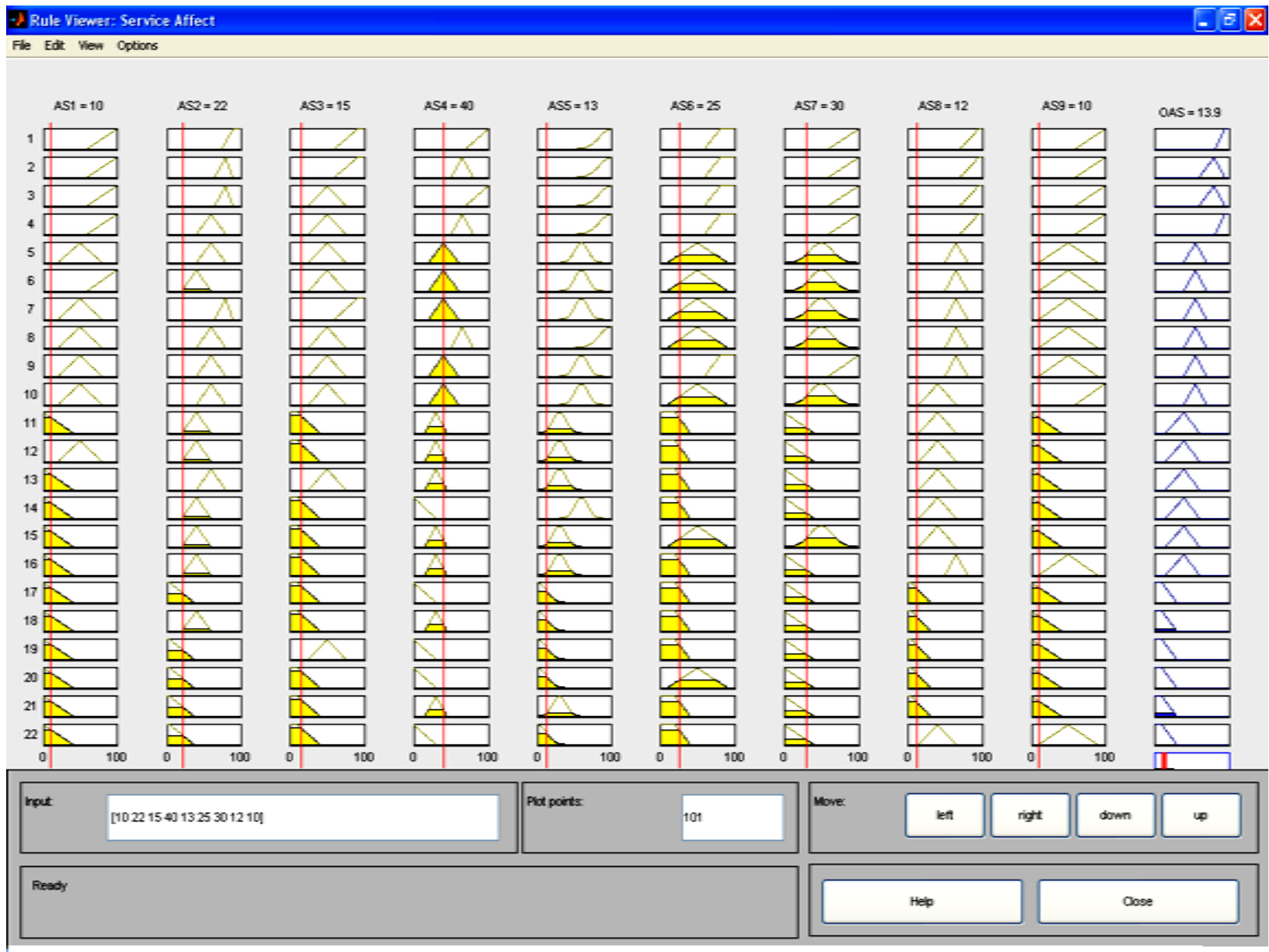

Figure 3. Fuzzy rules set of service effectiveness system.

The LP5 (A getaway for study, learning or research) input has 4 fuzzy membership functions including (BS, NS, GS, VGS). All input membership functions are trapezoidal. To fuzzification the LP5 input membership functions; following Equation 7 is used.

$$
\begin{aligned}
& \mu_{B S}(L P 5)=\left\{\begin{array}{cc}
0 & x<0 \\
1 & 0 \leq x<10 \\
\frac{30-x}{20} & 10<x \leq 30
\end{array} \quad \mu_{N S}(L P 5)=\left\{\begin{array}{cc}
\frac{x-15}{25} & 15 \leq x<40 \\
1 & 40 \leq x \leq 50 \\
\frac{65-x}{15} & 50<x \leq 65
\end{array}\right.\right. \\
& \mu_{G S}(L P 5)=\left\{\begin{array}{cl}
\frac{x-51}{19} & 51 \leq x<70 \\
1 & 70 \leq x \leq 75 \\
\frac{90-x}{15} & 75<x \leq 90
\end{array} \quad \mu_{V G S}(L P 5)=\left\{\begin{array}{cc}
\frac{x-80}{15} & 80 \leq x<95 \\
1 & 95 \leq x \leq 100 \\
0 & x<80
\end{array}\right.\right.
\end{aligned}
$$

The LP output has 4 fuzzy membership functions including (VB, B, $G$, and $V G)$. All output membership functions are triangular. To fuzzification the LP output membership functions, following Equation 8 is used. 


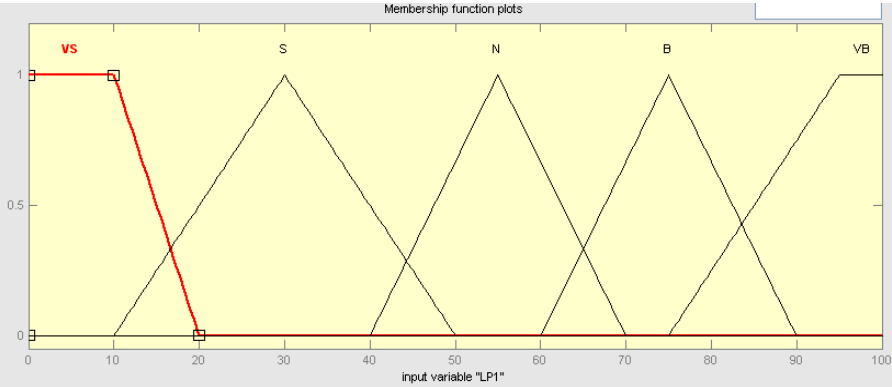

(LP1)

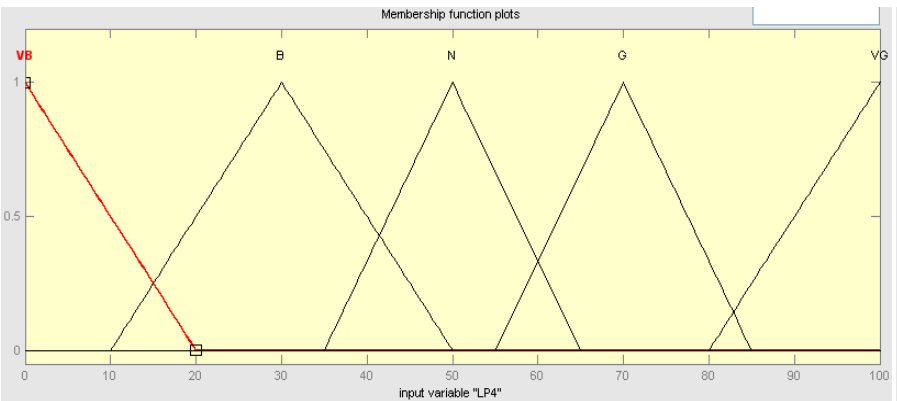

(LP4)

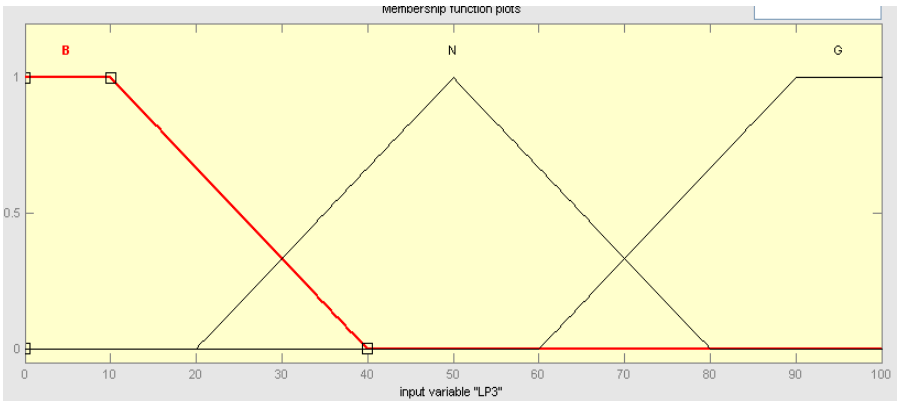

(LP3)

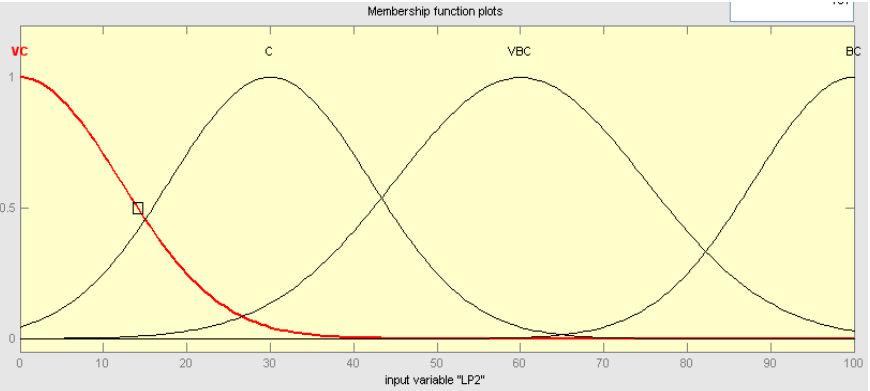

(LP2)

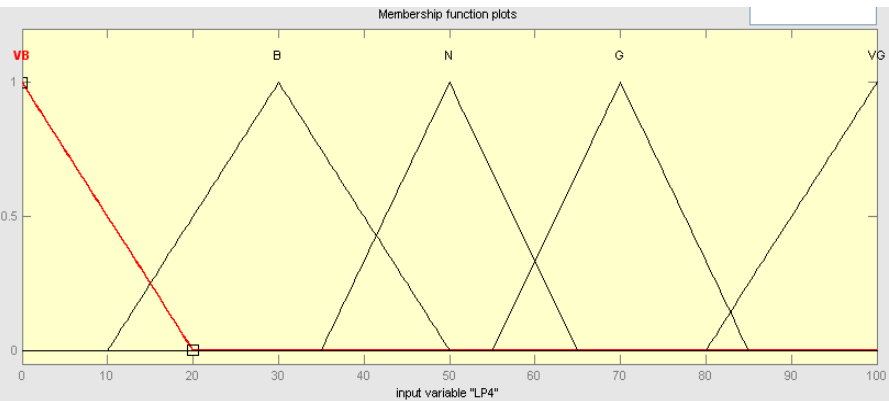

(LP5)

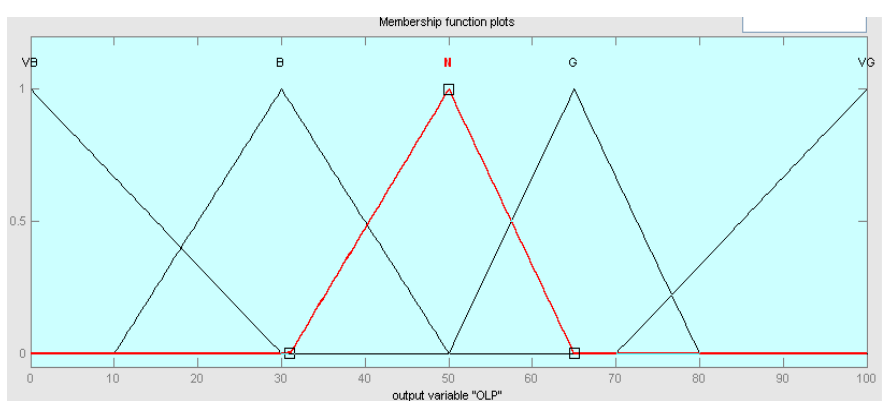

Out $\mathrm{p}$ ut (LP)

Figure 4. Fuzzy inputs of library place system.

Output of Library as place (8)

$$
\begin{gathered}
\mu_{V B}(\text { out_LP })=\left\{\begin{array}{cc}
0 & x<0 \\
\frac{30-x}{30} & 0 \leq x<30
\end{array} \quad \mu_{B}(\text { out_LP })= \begin{cases}\frac{x-10}{20} & 10 \leq x<30 \\
\frac{50-x}{20} & 30 \leq x<50\end{cases} \right. \\
\mu_{N}(\text { out_LP })=\left\{\begin{array}{ll}
\frac{x-31}{19} & 31 \leq x<50 \\
\frac{65-x}{15} & 50 \leq x \leq 65
\end{array} \mu^{(\text {out }}-L P\right)=\left\{\begin{array}{ll}
\frac{x-50}{30} & 50 \leq x<65 \\
\frac{80-x}{15} & 65 \leq x \leq 80
\end{array} \quad \mu_{V G}(\text { out } L P)=\left\{\begin{array}{cc}
0 & 100<x \\
\frac{x-70}{30} & 70 \leq x \leq 100
\end{array}\right.\right.
\end{gathered}
$$

This system has 27 fuzzy rules. All rules have the same weight (equal to one). The fuzzy rules are presented in Figure 5. By using surface viewer option in FIS toolkit, a graphical pattern of the relationship between two inputs and the output of the system can be observed. Figure 6 illustrates the relationship the LP5 and LP2 inputs with the output.

\section{Information control fuzzy system}

The present century is known as the information world. At the present time, countries with further modern knowledge are more successful in the field of economy as well as management. Library as a place for interchanging and controlling the information has a 
1. If (LP1 is VS) and (LP2 is VC) and (LP3 is G) and (LP4 is VG) and (LP5 is VGS) then (OLP is VG) (1)

2. If (LP1 is VS) and (LP2 is VC) and (LP3 is G) and (LP4 is VG) and (LP5 is GS) then (OLP is VG) (1)

3. If (LP1 is VS) and (LP2 is VC) and (LP3 is G) and (LP4 is G) and (LP5 is VGS) then (OLP is VG) (1)

4. If (LP1 is VS) and (LP2 is C) and (LP3 is G) and (LP4 is VG) and (LP5 is VGS) then (OLP is VG) (1)

5. If (LP1 is S) and (LP2 is VC) and (LP3 is G) and (LP4 is VG) and (LP5 is VGS) then (OLP is VG) (1)

6. If (LP1 is N) and (LP2 is VC) and (LP3 is G) and (LP4 is VG) and (LP5 is VGS) then (OLP is VG) (1)

7. If (LP1 is S) and (LP2 is C) and (LP3 is G) and (LP4 is G) and (LP5 is GS) then (OLP is G) (1)

8. If (LP1 is VS) and (LP2 is C) and (LP3 is G) and (LP4 is G) and (LP5 is GS) then (OLP is G) (1)

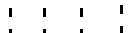

$: \vdots: \vdots$

$: ;$

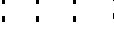

i i i i

21. If ( $L P 1$ is $B)$ and ( $L P 2$ is $B C)$ and (LP3 is $N)$ and (LP4 is $B)$ and (LP5 is BS) then (OLP is B) (1)

22. If ( $L P 1$ is $B$ ) and (LP2 is $B C$ ) and (LP3 is $B)$ and (LP4 is VB) and (LP5 is BS) then (OLP is B) (1)

23. If (LP1 is B) and (LP2 is BC) and (LP3 is B) and (LP4 is B) and (LP5 is NS) then (OLP is B) (1)

24. If (LP1 is VB) and (LP2 is VBC) and (LP3 is B) and (LP4 is VB) and (LP5 is BS) then (OLP is VB) (1)

25. If (LP1 is B) and (LP2 is VBC) and (LP3 is B) and (LP4 is VB) and (LP5 is BS) then (OLP is VB) (1)

26. If ( $L P 1$ is VB) and (LP2 is BC) and (LP3 is $B$ ) and (LP4 is VB) and (LP5 is BS) then (OLP is VB) (1)

27. If (LP1 is VB) and (LP2 is VBC) and (LP3 is B) and (LP4 is B) and (LP5 is BS) then (OLP is VB) (1)

Figure 5. Fuzzy rules of library as place system.

significant role respectively. It is the most important scientific and research center in developing countries. The existence of digital information resources, new scientific journals and so on can enhance the level of users' satisfaction. Moreover, the existence of facilities used to provide rapid access to resources and information helps users save the time and meet their information needs more swiftly.

This fuzzy system has 8 inputs which are explained in Table 4. Figure 7 illustrates all fuzzy inputs of this system.
In designing fuzzy inputs, different kinds of membership functions are tested in order to determine the best one. Each of fuzzy membership functions has its own specific characteristics which help the fuzzification process. Inputs fuzzification is done based on the experiences of library experts as well as the opinions of students. IC1 input has 3 triangular fuzzy membership functions. These membership functions are high $(\mathrm{H})$, normal $(\mathrm{N})$, and low $(\mathrm{L})$. To fuzzification these functions Equations 9 is applied.

(IC1) Print and/or electronic journal collections (9)

$$
\mu_{L}(I C 1)=\left\{\begin{array}{ccc}
0 & x<0 \\
1 & x=0 \\
\frac{40-x}{40} & 0<x \leq 40
\end{array} \quad \mu_{N}(I C 1)=\left\{\begin{array}{cc}
\frac{x-20}{30} & 20 \leq x<50 \\
\frac{80-x}{30} & 50 \leq x<80
\end{array} \quad \mu_{H}(I C 1)=\left\{\begin{array}{cc}
0 & x<0 \\
1 & x=100 \\
\frac{x-60}{40} & 60 \leq x<100
\end{array}\right.\right.\right.
$$

IC2 input has 5 trapezoidal fuzzy membership functions. These these functions Equations 10 is applied.

membership functions are VL, L, N, H, and VH. To fuzzification

(IC2) The printed library materials I need for my work (10)

$$
\begin{gathered}
\mu_{V L}(I C 2)=\left\{\begin{array}{cc}
0 & x<0 \\
1 & 0 \leq x \leq 10 \\
\frac{25-x}{15} & 10<x \leq 25
\end{array} \quad \mu_{L}(I C 2)=\left\{\begin{array}{cc}
\frac{x-15}{15} & 15 \leq x<30 \\
1 & 30 \leq x \leq 34 \\
\frac{50-x}{16} & 34 \leq x<5 C
\end{array} \mu_{N}(I C 2)=\left\{\begin{array}{cc}
\frac{x-40}{10} & 40 \leq x<50 \\
1 & 50 \leq x \leq 55 \\
\frac{65-x}{10} & 55 \leq x<65
\end{array}\right.\right.\right. \\
\mu_{H}(I C 2)=\left\{\begin{array}{cc}
\frac{x-60}{10} & 60 \leq x<70 \\
1 & 70 \leq x \leq 75 \\
\frac{90-x}{15} & 75 \leq x<90
\end{array}\right.
\end{gathered}
$$




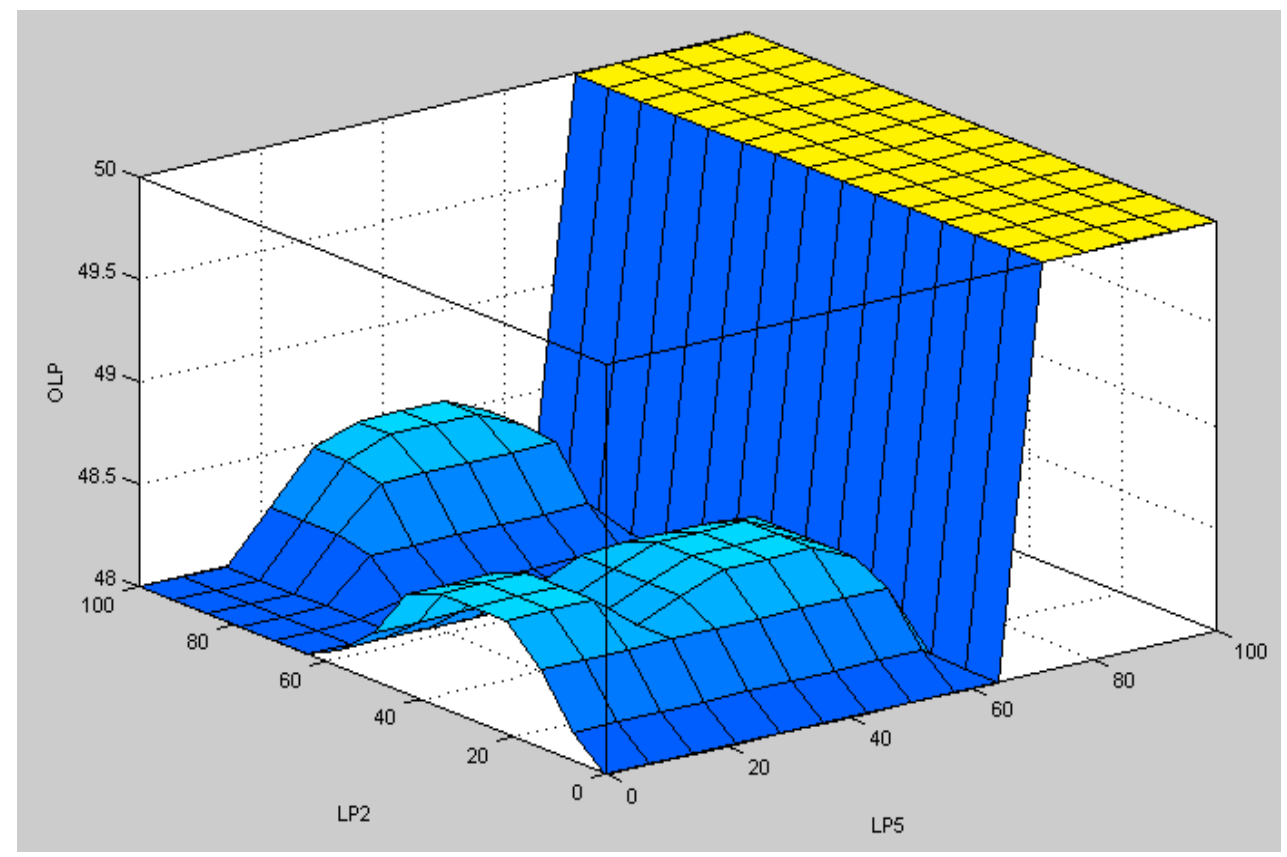

Figure 6. Relationship between Ip2 and Ip5 inputs with the output.

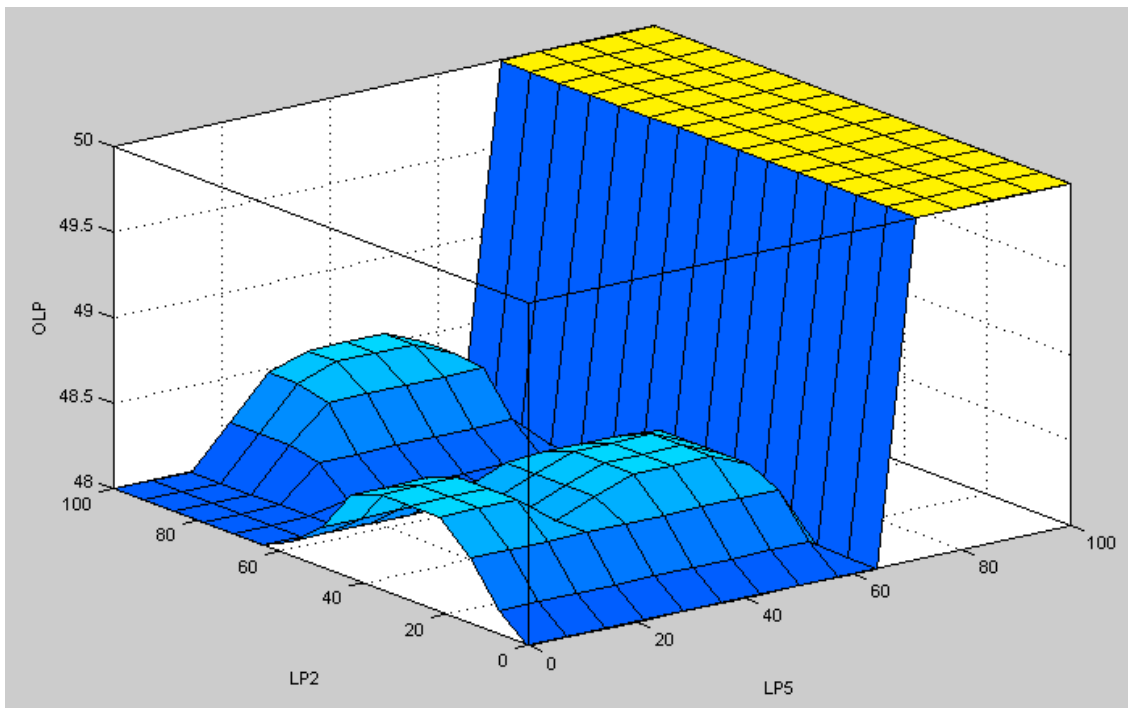

Figure 6. Relationship between Ip2 and Ip5 inputs with the output.

IC3 input has 3 Gaussian fuzzy membership functions. These

fuzzification these functions Equations 11 is applied. membership functions are few $(\mathrm{F})$, normal $(\mathrm{N})$, and many $(\mathrm{M})$. To

(IC3) The electronic information resources I need (11)

$$
\mu_{F}(I C 3)=e^{\frac{-(x-0)^{2}}{2^{*} 10^{2}}} \quad \mu_{N}(I C 3)=e^{\frac{-(x-50)^{2}}{2^{*} 15^{2}}} \quad \mu_{M}(I C 3)=e^{\frac{-(x-100)^{2}}{2 * 12^{2}}}
$$

IC4 input has 5 triangular fuzzy membership functions. These membership functions are very easy (VE), easy (E), normal (N), high $(\mathrm{H})$, and very high $(\mathrm{VH}))$. To fuzzification these functions Equations 12 is applied. 
(IC4) Easy-to-use access tools (12)

$$
\begin{gathered}
\mu_{V E}(\text { IC } 4)=\left\{\begin{array}{cc}
0 & x<0 \\
\frac{30-x}{30} & 0 \leq x<30
\end{array} \quad \mu_{E}(\text { IC } 4)=\left\{\begin{array}{cc}
\frac{x-10}{15} & 10 \leq x<25 \\
\frac{40-x}{15} & 25 \leq x<40
\end{array}\right.\right. \\
\mu_{N}(I C 4)=\left\{\begin{array}{ll}
\frac{x-30}{20} & 30 \leq x<50 \\
\frac{70-x}{20} & 50 \leq x \leq 70
\end{array} \quad \mu_{H}(\text { IC } 4)=\left\{\begin{array}{cc}
\frac{x-60}{10} & 60 \leq x<70 \\
\frac{80-x}{10} & 70 \leq x \leq 80
\end{array} \quad \mu_{V H}(\text { IC } 4)=\left\{\begin{array}{cc}
0 & 100<x \\
\frac{x-70}{30} & 70 \leq x \leq 100
\end{array}\right.\right.\right.
\end{gathered}
$$

According to Figure 7, the triangular, trapezoidal and Gaussian membership functions are also used with other inputs of the IC system. To fuzzification them, the fuzzification equations similar to previous equations are used which are not discussed again in order to avoid repetition.

This system has 14 fuzzy rules. It was examined with different values and the results of system testing are presented in Figure 8.

\section{Library service quality fuzzy system}

This system has three inputs and one output. In fact, the inputs are the outputs of previous three systems. The system's output is the level of users' satisfaction. Figure 9 shows the library service quality fuzzy system.

In order to specify the level of users' satisfaction on library services, the fuzzy membership functions (Figure 10) is applied. These functions are related to output of library services system.

To fuzzification the inputs, the equations related to three previous systems output are utilized. In addition, to fuzzification the output of this system, Equation 13 is applied.

Output (Library service quality fuzzy system) (13)

$$
\begin{gathered}
\mu_{L}\left(O_{-} L S Q\right)=\left\{\begin{array}{cc}
0 & x<0 \\
1 & 0 \leq x \leq 5 \\
\frac{25-x}{20} & 5<x \leq 25
\end{array}\right. \\
\mu_{H}\left(O_{-} L S Q\right)=\left\{\begin{array}{cc}
\frac{x-40}{25} & 40 \leq x<65 \\
\frac{85-x}{20} & 65 \leq x<85
\end{array}\right.
\end{gathered}
$$

This system has 22 fuzzy rules. All rules have the same weight (equal to one). To create relationship between the inputs, an and operator is used. Figure 11 shows the set of fuzzy rules of library services quality system.

\section{EXPERIMENTAL RESULTS}

This system is designed taking into consideration the experiences of librarianship science experts in addition to the questionnaires filled out by university students of (Shirvan Islamic Azad University, Bojnourd Islamic Azad University, Bojnourd University and Mashhad Islamic Azad University). The required data for grading the dimensions of library service quality is gathered by performing LibQUAL ${ }^{+T M}$ questionnaire. Since, the mentioned questionnaire is used by several researchers in various studies; its validity can be approved per se. There are different techniques including "Cronbach's alpha" for calculating the reliability of data gathering instruments. In

$$
\begin{gathered}
\mu_{N}\left(O_{-} L S Q\right)=\left\{\begin{array}{cc}
\frac{x-10}{25} & 10 \leq x<35 \\
\frac{60-x}{25} & 35 \leq x<60
\end{array}\right. \\
\mu_{V H}\left(O_{-} L S Q\right)=\left\{\begin{array}{cc}
\frac{x-70}{25} & 70 \leq x<95 \\
1 & 95 \leq x \leq 100 \\
0 & x>100
\end{array}\right.
\end{gathered}
$$

this technique, the closer the value is to $100 \%$, the greater validity of the questionnaire is reflected. In this research, Cronbach's Alpha is used to determine the reliability of questionnaire.

Different values are used to test the system so as to examine its weakness and strength points. These values are selected from different statements such as when the level of satisfaction is low, medium, high, and very high in order to evaluate the performance of system in different conditions. The results obtained by applying hybrid fuzzy expert system are compared with the average value of the opinions of library experts.

In order to examine the performance of this system, we should first test each system considering different data, and then insert the outputs of the three systems to the final system in order to obtain the final result. All the mentioned steps are repeated 8 times to assess the general performance of the system. Table 5 presents the service effect system testing results for 8 data sets. In 

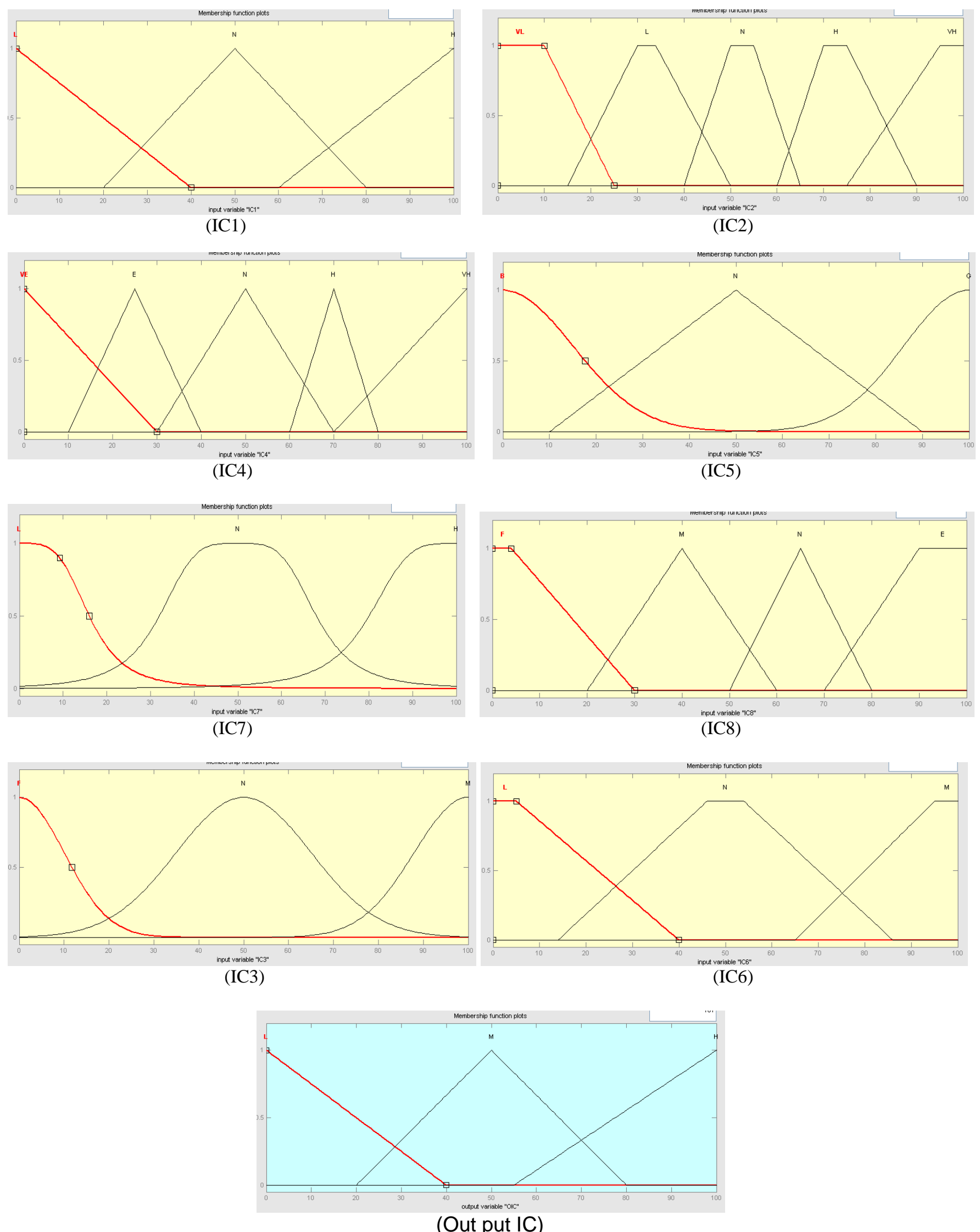

Figure 7. Fuzzy inputs of information control system. 


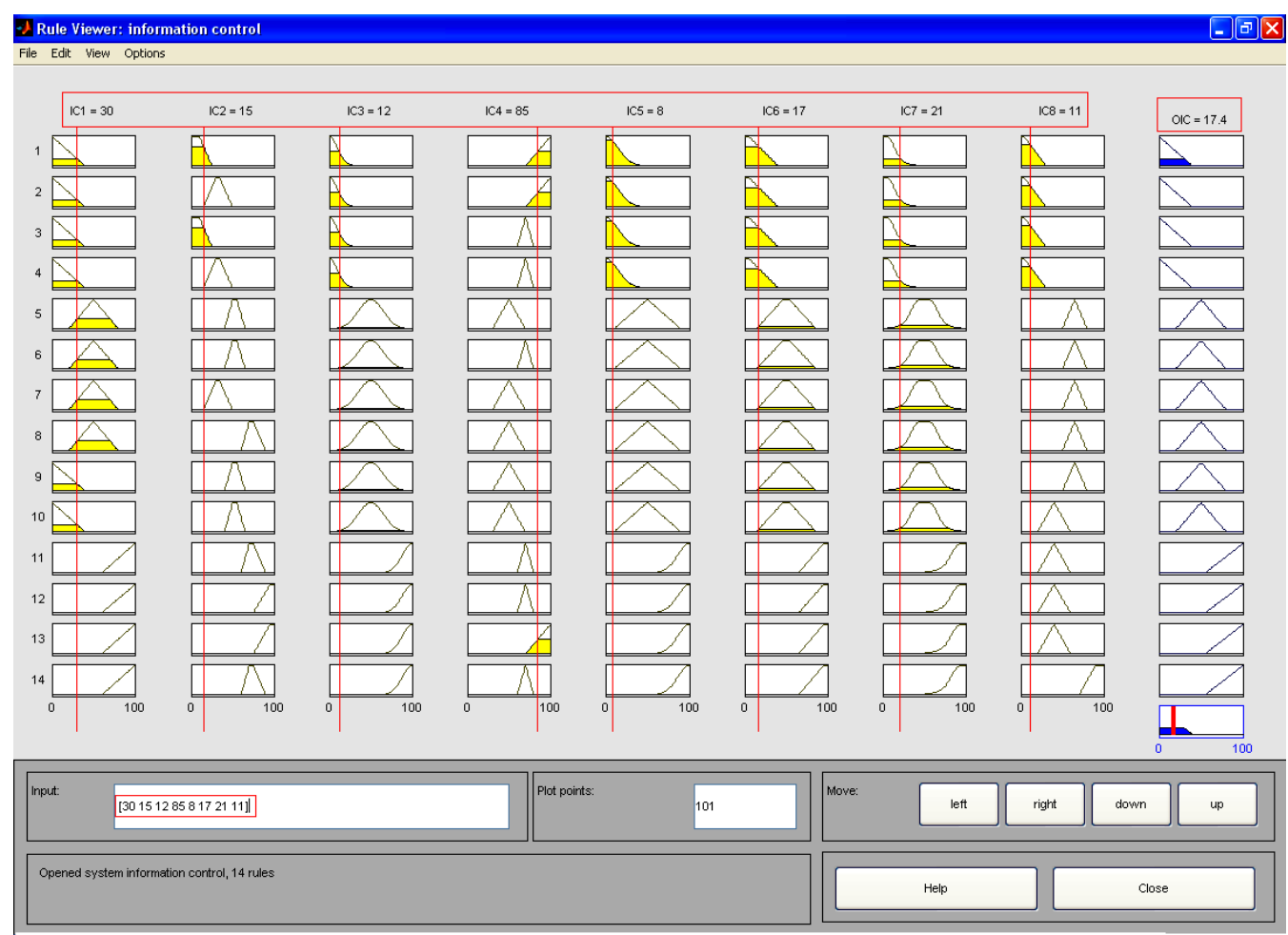

(a)

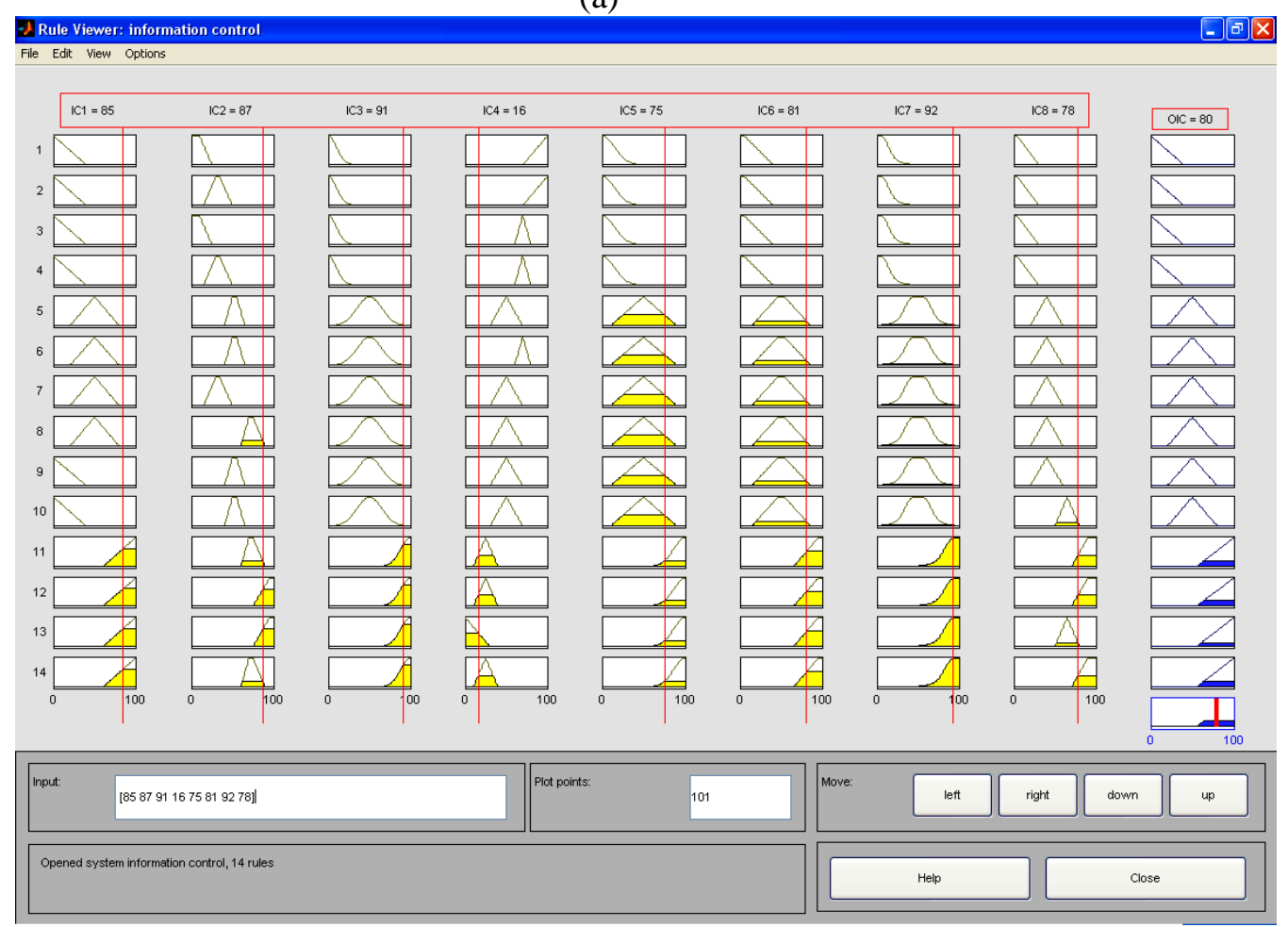

(b)

Figure 8. (a) System testing with low values where there is little satisfaction; (b) System testing with high values where there is good satisfaction.

this Table, the average of library experts' opinions is also presented to examine the accuracy of system. The average error of system is 0.98 which indicates that the performance of fuzzy expert system is very good. 


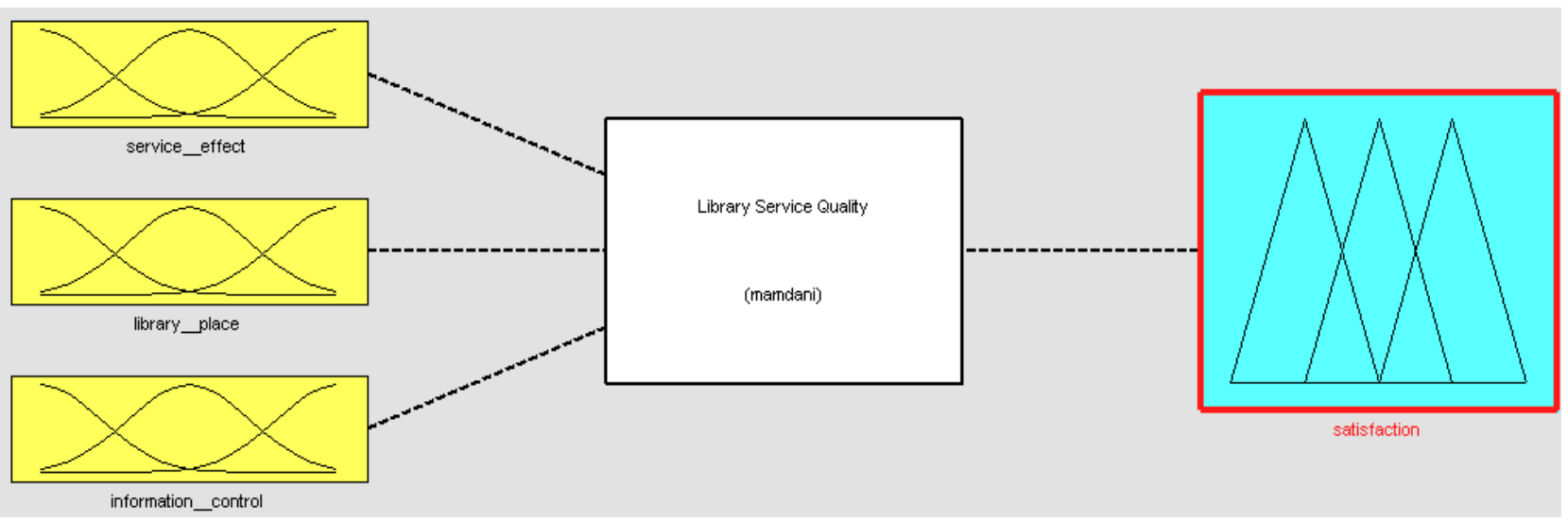

Figure 9. Library service quality fuzzy system.

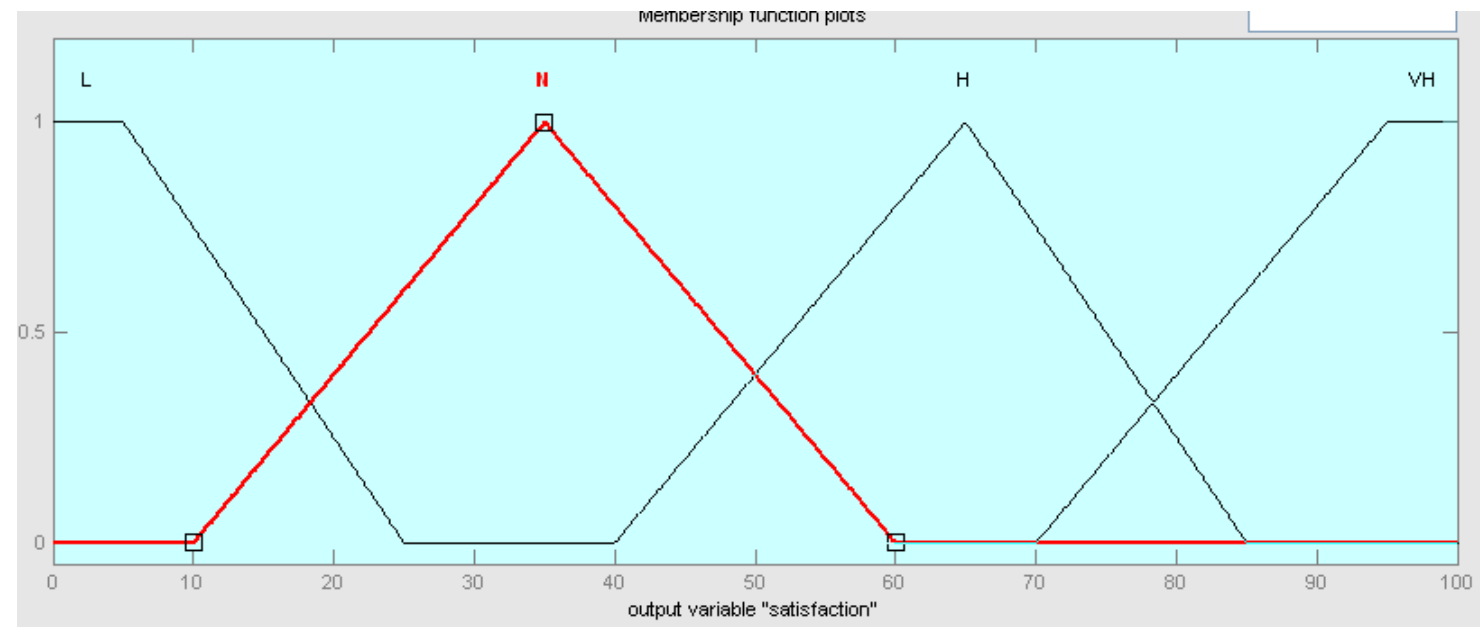

Figure 10. Fuzzy membership functions of library service quality system output.

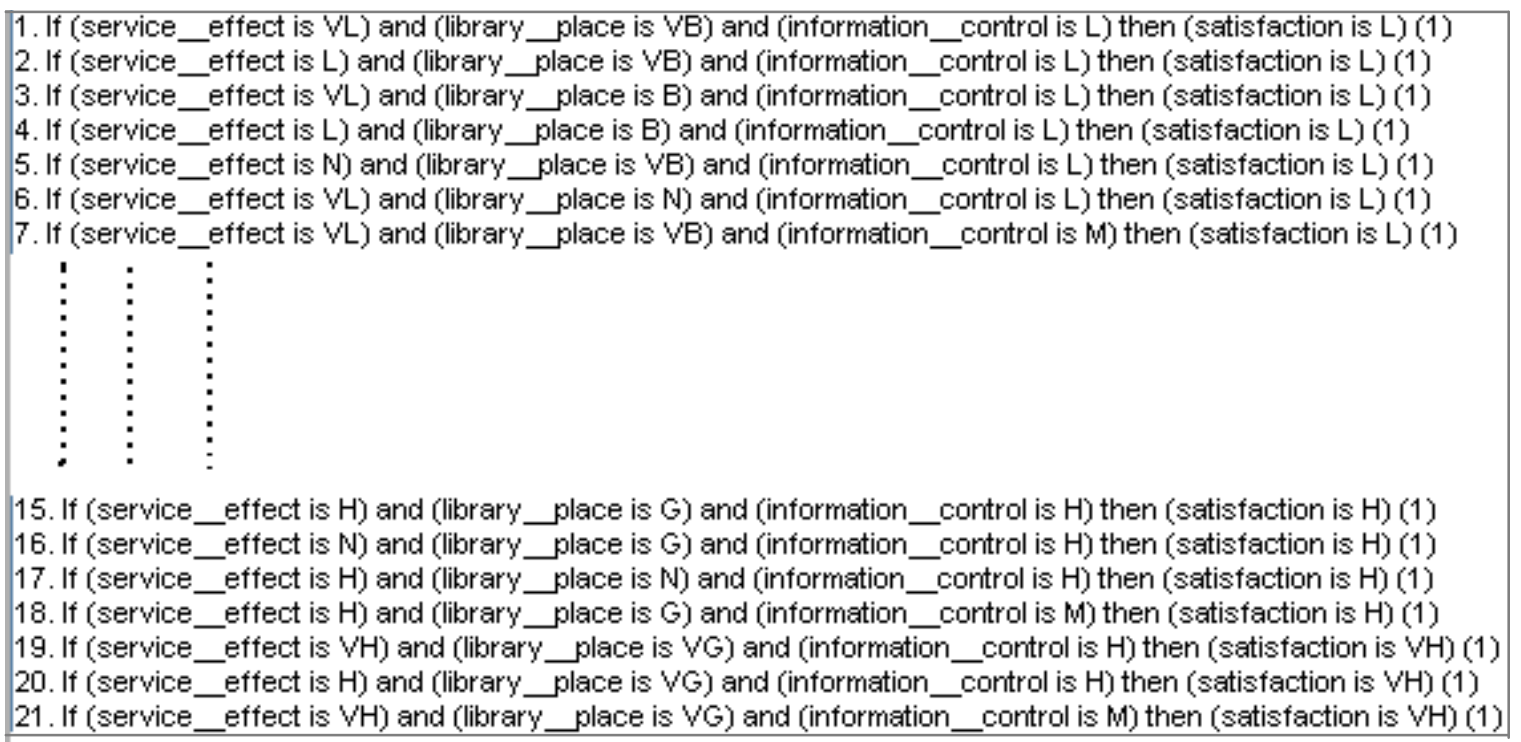

Figure 11. Set of fuzzy rules of library service quality system. 
Table 5. Illustration of the results of service effect fuzzy system's teaching.

\begin{tabular}{cccccccccccc}
\hline \# & AS9 & AS1 & AS2 & AS3 & AS5 & AS6 & AS7 & AS8 & AS9 & Result's system & Average experts \\
\hline T1 & 32 & 11 & 22 & 8 & 15 & 17 & 25 & 13 & 31 & 13.8 & 15.2 \\
T2 & 27 & 22 & 55 & 7 & 12 & 11 & 32 & 16 & 22 & 15.2 & 16.8 \\
T3 & 21 & 29 & 24 & 19 & 42 & 29 & 27 & 42 & 27 & 33.3 & 34.5 \\
T4 & 15 & 43 & 73 & 23 & 37 & 31 & 21 & 38 & 25 & 32.7 & 31.5 \\
T5 & 50 & 60 & 50 & 40 & 60 & 80 & 97 & 65 & 50 & 56.5 & 56.4 \\
T6 & 56 & 80 & 81 & 46 & 58 & 72 & 55 & 61 & 66 & 55 & 56.2 \\
T7 & 97 & 65 & 65 & 78 & 76 & 81 & 91 & 79 & 73 & 91.7 & 90.7 \\
T8 & 83 & 87 & 79 & 91 & 86 & 91 & 72 & 95 & 89 & 92.2 & 94.5 \\
\hline
\end{tabular}

Table 6. Illustration of the results of library place fuzzy system's testing.

\begin{tabular}{cccccccc}
\hline \# & LP1 & LP2 & LP3 & LP4 & LP5 & Result's system & Average experts \\
\hline T1 & 83 & 73 & 59 & 29 & 7 & 30 & 29.8 \\
T2 & 78 & 58 & 21 & 32 & 15 & 27.7 & 26.1 \\
T3 & 63 & 50 & 32 & 43 & 47 & 48.2 & 51.4 \\
T4 & 52 & 36 & 47 & 61 & 43 & 48.3 & 50.2 \\
T5 & 41 & 23 & 83 & 55 & 65 & 63.5 & 63.1 \\
T6 & 35 & 19 & 90 & 73 & 70 & 65 & 65.7 \\
T7 & 21 & 16 & 76 & 86 & 93 & 87.4 & 85.2 \\
T8 & 15 & 10 & 80 & 90 & 87 & 88.4 & 89.6 \\
\hline
\end{tabular}

Table 6 these findings clearly represent the performance of system. T1 and 2 states signify the situations where the level of users' satisfaction on library place facilities is low. T3 and 4 states refer to medium satisfaction, and T5 and 6 imply high level of satisfaction. T7 and 8 indicate the very high level of satisfaction.

After comparing the results obtained by the system with the average of library experts' opinions, the average error of 1.425 is observed. This amount of error in the opinions of experts is acceptable and the performance of system is reported as good. Table 7 shows the results of information control system testing. T1, 2, and 3 states signify the situations where the level of satisfaction is low. In T4 and 5, the level of satisfaction is medium, and in T6, T and 8 states the level of satisfaction is high. The average error of this system is 0.887 which according to opinions of library experts is acceptable and very low. Figure 12 indicates a view of T8 state.

Now, in order to evaluate the final performance of this hybrid fuzzy system, we insert the results obtained from these three systems to library service quality fuzzy system. Table 8 shows the results of library service quality system, reflecting its performance in 8 different states. The average error of overall system is 1.097. It means that the performance of this hybrid fuzzy system is $98.003 \%$ accurate.

\section{Conclusion}

In this paper, a hybrid fuzzy expert system was developed to evaluate the academic library service quality. This system is a combination of 4 fuzzy inference systems, each of which has some inputs and one output. The final output is the level of users' satisfaction on library services. The required data for grading the dimensions of library services was gathered through performing LibQUAL ${ }^{+T M}$ questionnaire. Since the mentioned questionnaire has been used by several researchers in various studies, its validity is already approved. In order to calculate the reliability of data gathering instruments, "Cronbach's alpha" method was applied.

Using fuzzy inference system in this study made possible the flexibility and modeling of indeterminate data. In order to design fuzzy rules, the opinions of librarianship science experts and students were taken into consideration. After the design stage, individual systems were tested in different situations. The results obtained from the systems were compared to the average opinions of experts and students and the error of each system was calculated. The overall average error of this system is $98.003 \%$. This error is insignificant and acceptable from the experts' point of view. This system can estimate the level of users' satisfaction by evaluating the library service quality. This increases the efficiency and quality of academic library services. Application of other artificial intelligence methods such as neural networks, genetic algorithm and so on is good area for further studies. It is hoped that better intelligence systems would be designed by using such methods. 
Table 7. Results of information control system testing.

\begin{tabular}{ccccccccccc}
\hline \# & IC1 & IC2 & IC3 & IC4 & IC5 & IC6 & IC7 & IC8 & Result's system & Average experts \\
\hline T1 & 15 & 12 & 8 & 87 & 10 & 15 & 19 & 8 & 16.6 & 17.5 \\
T2 & 21 & 25 & 7 & 73 & 15 & 26 & 21 & 13 & 17.3 & 17 \\
T3 & 8 & 30 & 15 & 73 & 22 & 17 & 13 & 26 & 18.2 & 17.5 \\
T4 & 35 & 46 & 41 & 75 & 36 & 42 & 31 & 39 & 50 & 52.1 \\
T5 & 53 & 79 & 52 & 55 & 61 & 55 & 55 & 47 & 53 & 54.2 \\
T6 & 82 & 80 & 83 & 25 & 70 & 76 & 83 & 83 & 78.9 & 78.6 \\
T7 & 89 & 93 & 87 & 21 & 85 & 82 & 72 & 90 & 80 & 81 \\
T8 & 91 & 95 & 91 & 10 & 90 & 93 & 89 & 65 & 84 & 83.4 \\
\hline
\end{tabular}

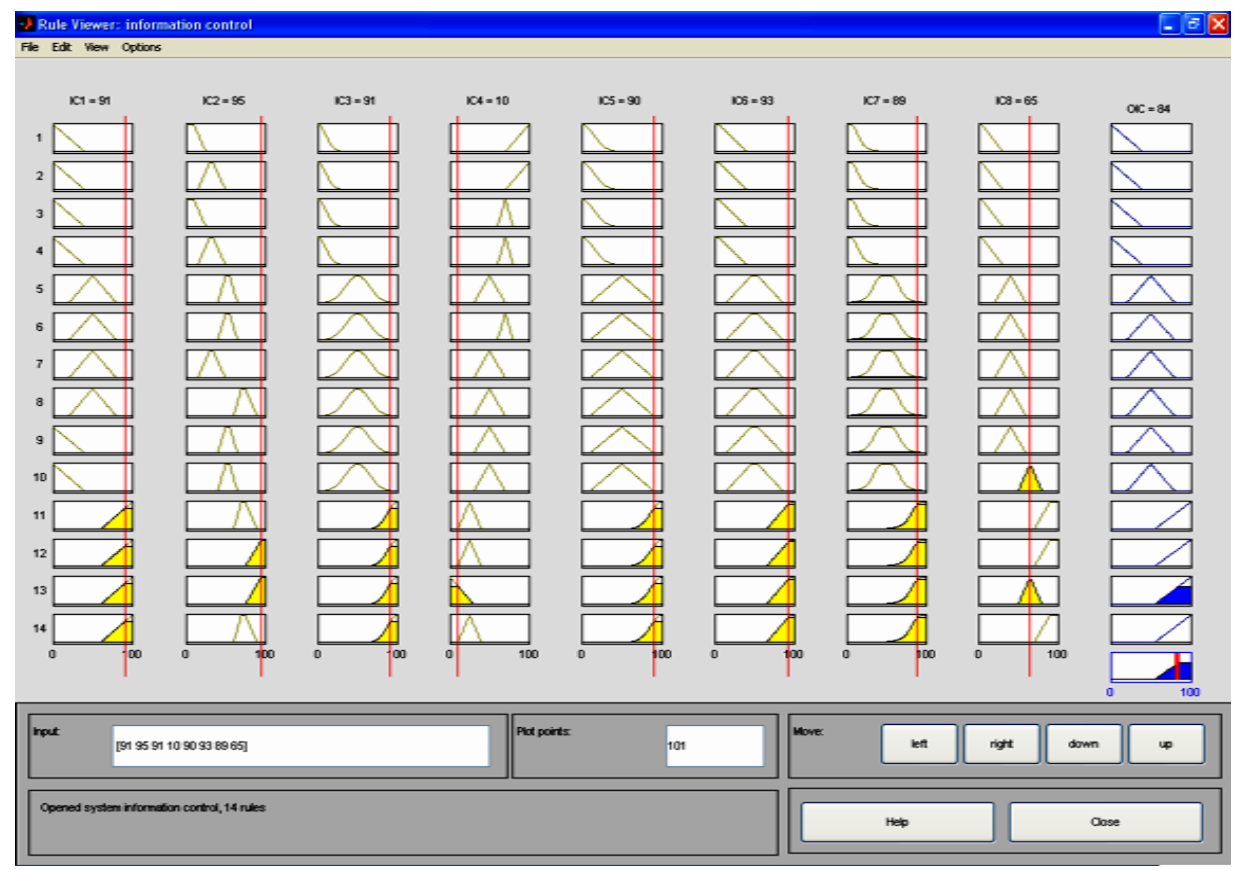

Figure 12. T8 State of information control fuzzy system.

Table 8. Results of library service quality system.

\begin{tabular}{ccccc}
\hline$\#$ & Service effect & Library place & Information control & Result's system \\
\hline T1 & 13.8 & 30 & 16.6 & 11.5 \\
T2 & 15.2 & 27.7 & 17.3 & 12 \\
T3 & 33.3 & 48.2 & 18.2 & 14.2 \\
T4 & 32.7 & 48.3 & 50 & 45 \\
T5 & 56.5 & 63.5 & 53 & 48.2 \\
T6 & 55 & 65 & 78.9 & 64.6 \\
T7 & 91.7 & 87.4 & 80 & 88.4 \\
T8 & 92.2 & 88.4 & 84 & 88.7 \\
\hline
\end{tabular}

\section{REFERENCES}

Bertot JC (2004). "Assessing Digital Library Services: Approaches, Issues, and Considerations", International Symposium on Digital Libraries and Knowledge Communities in Networked Information Society (DLKC'04).
Calvert PJ (2008). "Assessing The Effectiveness And Quality Of Libraries", A thesis submitted to the Victoria University of Wellington, requirements of Doctor of Philosophy in Information Systems.

Cook C, Heath FM, Thompson B, Thomson R (2001a). "LibQUAL ${ }^{+T M}$. service quality assessment in research libraries", IFLA J. 4:256-268.

Cook C, Heath FM (2001b). "Users' perceptions of library service 
quality". Lib. Trends 49(4):538-584.

Cook C, Heath F, Kyrillidou M, Thompson B, Thompson R (2001c). "The search for new measures: the ARL LibQUAL" study a preliminary report", portal: Lib. Acad. 1:103-112.

Cook C, Heath FM, Thompson B (2003a). Developing a National Science Digital Library (NSDL) LibQUAL+TM Protocol An E-service for Assessing the Library of the 21st Century", NSDL Evaluation Workshop.

Cook C, Heath F, Thompson B (2003b). "Zones of tolerance' in perceptions of library service quality: a LibQUAL ${ }^{+T M}$ study", portal: Lib. Acad. 3:113-123.

Cook C, Heath FM, Thompson B (2002) "Score norms for improving library service quality: A LibQUAL ${ }^{+T M}$ study". Portals: Lib. Acad. 2(1):13-26.

Dodangeh J, Yusuff RMD, Jassbi J (2011). Assessment system based on fuzzy scoring in European Foundation for Quality Management (EFQM) business excellence model. 4 August. Afr. J. Bus. Manag. 5(15):6209-6220.

Gopalakrishnan S, Raghavan KS (2003). "Library Software Selection: A Fuzzy Logic Approach".

Heath F, Cook C, Kyrillidou M, Thompson B (2002). "ARL Index and other validity correlates of LibQUAL ${ }^{+}$scores", portal: Lib. Acad. 2:2742.

Hernon P, Altman E (1996). "Service quality in academic libraries". Norwood, NJ: Ablex.

Hernon P, Nitecki D, Altman E (1999). Service quality and customer satisfaction assessment and future directions", J. Acad. Librariansh 25:9-17.

Jamali R, Tooranloo HS (2009). "Prioritizing academic library service quality indicators using fuzzy approach: Case study: libraries of Ferdowsi University", Lib. Manag. 30(4/5):319-333.

Jiang H (2009). "Fuzzy Comprehensive Evaluation on Digital Libraries Based on Membership Degree Transformation New Algorithm-M $(1,2,3)$, "Electronic Commerce and Security, International. 2009 Second International Symposium on Electronic Commerce and Security. Symposium 2:488-492.

Kaplan RS, Norton DP (1996). "The Balanced scorecard: Translating strategy into action. Boston", MA: Harvard Business School Press.

Kiran K (2010). "Service quality and customer satisfaction in academic libraries: Perspectives from a Malaysian university", Lib. Rev. 59(4):261-273.

Kyrillidou M, Giersch S (2005). "Developing the DigiQUAL Protocol for Digital Library Evaluation", Proceedings of the 5th ACMIEEECS Joint Conference on Digital Libraries. Publisher: ACM Press pp.172-173.

Kyrillidou M, Lowry C, Hanges P, Aiken J, Justh K (2009). "ClimateQUAL ${ }^{\mathrm{TM}}$ : Organizational Climate and Diversity Assessment", Ass. Res. Lib. pp.202-296-2296.
Kyrillidou M, Olshen T, Heath F, Bonnelly C, Cote JP (2003). "CrossCultural Implementation of LibQUAL+TM: The French Language Experience." Paper presented at the $5^{\text {th }}$ North Umbria International Conference, Durham, UK, July 29.

Lin CT, Chiu H, Chu PY (2006). "Agility index in the supply chain ", Int. J. Prod. Econ., 100: 285-299.

Nimsomboon N, Nagata H (2003). Assessment of Library Service Quality At Thammasat University Library System, www.kc.tsukuba.ac.jp/div-comm/pdf/report0403.pdf. Res. Report, pp. 1-73.

Parasuraman A, Berry L, Zeithaml VA (1985). "A Conceptual Model of Service Quality and Its Implications for Future Research," J. Mark., 49: 41-50.

Parasuraman A, Berry L, ZeithamI VA (1988). "SERVQUAL: A Multipleitem Scale for Measuring Consumer Perceptions of Service Quality," J. Retail., 64: 12-40.

Perez IJ, Viedma EH, Lopez-Gijon J, Cabrerizo FJ (2010). "A New Application of a Fuzzy Linguistic Quality Evaluation System in Digital Libraries", IEEE international conference intelligence systems design and applications (ISDA), Cairo, pp. 639-644.

Sahu AK (2007). 'Measuring service quality in an academic library: an Indian case study', Library Review, Vol.56, No.3, pp. 234-243.

Self $J$ (2003), from values to metrics: "Implementation of the balanced scorecard at a university library". Perform. Measure. Metrics, 4(2): 57-63.

Shahraki AR, Yaghoobi NM, Fard SG (2011)," Fuzzy Evaluation to Reach the Required Agility at Manufacturing Organizations", J. Basic. Appl. Sci. Res., 1(9): 1112-1123.

Shi X, Levy S (2005), "A theory-guided approach to library services assessment". Coll. Res. Lib., 66(3): 266-277.

Thompson B (2007). "The origins/birth of LibQUAL ${ }^{+T M ", ~ a v a i l a b l e ~ a t: ~}$ www.coe.tamu.edu/ bthompson/libbirth.htm.

Thompson B, Kyrillidou M, Cook C (2008). "Library users' service desires: a LibQUAL ${ }^{+}$study", Lib. Q. 1:1-18.

Thompson B, Kyrillidou M, Cook C (2006). "How you can evaluate the integrity of your library service quality assessment data intercontinental libqual analyses used as concrete", paper presented at the library assessment conference: Building Effective, sustainable, practical assessment, Charlottesville, VA.

Thompson B, Kyrillidou M, Cook C (2009). "Item sampling in service quality assessment surveys to improve response rates and reduce respondent burden The "LibQUAL ${ }^{+T M}$ Lite" example", Perform. Measure. Metrics 10(1): 6-16.

Waller CA, Hoseth A, Kyrillidou M (2003). LibQUAL ${ }^{+T M}$ policies and procedures manual ", Washington D.C. 